\title{
Landslides
}

\section{Remote analysis of an open-pit slope failure: Las Cruces case study, Spain --Manuscript Draft--}

\section{Manuscript Number:}

Full Title:

\section{Article Type:}

Order of Authors:

Corresponding Author:

\section{Corresponding Author Secondary}

Information:

\section{Corresponding Author's Institution:}

Corresponding Author's Secondary Institution:

First Author:

First Author Secondary Information:

Order of Authors Secondary Information:

\section{Funding Information:}

Abstract:
Remote analysis of an open-pit slope failure: Las Cruces case study, Spain

Original Paper

Juan López-Vinielles, M.D. (MSc)

Pablo Ezquerro

José A. Fernández-Merodo

Marta Béjar-Pizarro

Oriol Monserrat

Anna Barra

Pablo Blanco

Javier García-Robles

Antón Filatov

Juan C. García-Davalillo

Roberto Sarro

Joaquín Mulas

Rosa M. Mateos

José M. Azañón

Jorge P. Galve

Gerardo Herrera

Juan López-Vinielles, M.D. (MSc)

Instituto Geologico y Minero de Espana

Madrid, Madrid SPAIN

Instituto Geologico y Minero de Espana

Juan López-Vinielles, M.D. (MSc)

\begin{tabular}{|c|c|}
\hline $\begin{array}{l}\text { Comunidad de Madrid } \\
\text { (IND2017/AMB-7789) }\end{array}$ & Mr. Juan López-Vinielles \\
\hline $\begin{array}{l}\text { Directorate-General for Humanitarian Aid } \\
\text { and Civil Protection } \\
\text { (UCPM-2017-PP-AG) }\end{array}$ & Dr. Gerardo Herrera \\
\hline $\begin{array}{l}\text { Horizon } 2020 \text { Framework Programme (E- } \\
\text { SHAPE) } \\
\text { (820852) }\end{array}$ & Dr. Gerardo Herrera \\
\hline
\end{tabular}

Slope failures occur in open-pit mining areas worldwide producing considerable damage and economic losses. Identifying the triggering factors and detecting unstable slopes and precursory displacements, which can be achieved by exploiting remote sensing data, is critical to reduce their impact. Here we present a methodology that 
combines digital photogrammetry, satellite radar interferometry and geo-mechanical modeling, to perform remote analyses of slope instabilities in open-pit mining areas. We illustrate this approach by evaluating through back-analysis a massive landslide occurred in an active open-pit mine in southwest Spain in January 2019. Based on preand post-event high-resolution digital elevation models derived from digital photogrammetry, we estimate an entire sliding mass volume of around 14 million $\mathrm{m} 3$ . Radar interferometry reveals that the line of sight accumulated displacement in the slope during the year preceding the landslide reached -5.7 and $4.6 \mathrm{~cm}$ in ascending and descending geometry respectively, showing two acceleration events clearly correlated with rainfall in descending geometry. Through $3 \mathrm{D}$ and 2D stability analyses, we confirm the location of the slope instability and explain the progressive failure mechanism. A delayed collapse was triggered by rainfall events that progressively reduced suction on the sliding materials, which was also favored by their strainsoftening behavior. Finally, we discuss the potential of this methodological approach either to remotely perform post-event analyses of mining-related landslides and evaluate potential triggering factors, or to remotely identify critical slopes in mining areas and provide pre-alert warning. 
Madrid, $14^{\text {th }}$ January 2020

\section{Dear Editor,}

Please consider the article entitled "Remote analysis of an open-pit slope failure: Las Cruces case study, Spain" by the authors: Juan López-Vinielles, Pablo Ezquerro, José A. Fernández-Merodo, Marta Béjar-Pizarro, Oriol Monserrat, Anna Barra, Pablo Blanco, Javier García-Robles, Antón Filatov, Juan C. García-Davalillo, Roberto Sarro, Joaquín Mulas, Rosa M. Mateos, José M. Azañón, Jorge P. Galve, Gerardo Herrera for publication in Landslides Journal under the category Original Papers. This is an improved and extended version of the article "A recent massive landslide at Las Cruces open-pit mine (Seville, Spain)" (LASL-D-19-00404), which was rejected for publication in the form of a Recent Landslides article on 13 September 2019. Please, find below the reply received from the Editorial Office regarding the decision on this former article, including the reviewer comments, which have been properly addressed.

In the manuscript, we present a methodology that combines digital photogrammetry, satellite radar interferometry and geo-mechanical modelling to perform remote analyses of slope instabilities in open-pit mining areas. The usefulness of this approach either to remotely perform post-event analyses of miningrelated landslides and evaluate potential triggering factors, or to remotely identify critical slopes in mining areas and provide pre-alert warning, is demonstrated by evaluating a massive landslide occurred at Las Cruces open-pit mine in southwest Spain in January 2019. Our results, derived exclusively from the exploitation of remote sensed and published data, include considerations on geomorphic features, failure volumes, source areas, precursory displacements, accelerations related to rainfall, triggering factors and failure mechanisms.

The estimated volume of the entire sliding mass is about 14 million $\mathrm{m}^{3}$. Radar interferometry reveals that the line of sight accumulated displacement in the slope during the year preceding the landslide reached 5.7 and $4.6 \mathrm{~cm}$ in ascending and descending geometry respectively, showing two temporary acceleration events clearly correlated with rainfall in descending geometry. Through 2D and 3D stability analyses, we confirm the location of the slope instability and explain the progressive failure mechanism: a delayed collapse was triggered by a progressive pore-water pressure increase that reduced the suction force acting on the sliding materials, which was also favoured by their strain-softening behaviour. Thanks to the combined use of digital photogrammetry, satellite radar interferometry and geo-mechanical modelling, this study improves our understanding of mining slope instabilities under varying hydraulic and geotechnical conditions, which can help to improve their management. We confirm that this manuscript has not been published elsewhere and is not under consideration by another journal. All authors have approved the manuscript and agree with its submission to Landslides Journal.

We look forward to hearing from you soon.

Yours faithfully,

Juan López Vinielles (corresponding author)

Geohazards InSAR Laboratory and Modeling Group (InSARlab), Geoscience Research Department, Geological Survey of Spain (IGME), Alenza 1, 28003 Madrid, Spain. E-mail: jlvinielles@ gmail.com. Telephone: +34619547928 
Juan López

De: em.lasl.0.65ea0c.186e0b80@editorialmanager.com en nombre de Editorial Office em@editorialmanager.com

Enviado el: Friday, September 13, 2019 9:03 PM

Para: Juan López-Vinielles

Asunto: Decision on your Manuscript \#LASL-D-19-00404

Dear Mr. López-Vinielles:

We have received the reports from our advisors on your manuscript, "A recent massive landslide at Las Cruces openpit mine (Seville, Spain)."

With regret, I must inform you that based on the advice received your manuscript cannot be accepted for publication in Landslides.

Please find the reviewer comments below for your perusal or find it through attachment (If there is any).

I would like to thank you very much for forwarding your manuscript to us for consideration and wish you every success in finding an alternative place of publication such as SpringerPlus www.springerplus.com, or rewriting your paper referring to reviewer comments and contributing it as a new paper to "Technical Notes" or "Recent Landslides" (greater rate of Accept) or "Original papers" (smaller rate of Accept) to Landslides again.

Sincerely yours,

Editorial Board

Landslides

Reviewers' comments (if any):

Editor:

Dear Authors,

The manuscript was reviewed by an expert in the landslide research and the reviewer recommended rejection. I also reviewed the manuscript with interest and concur with the reviewer's recommendation. Specifically, the manuscript does not contain the sufficient detail to make this article a good recent landslide article. As such, with regret, I recommend rejection.

Yours sincerely,

Editor in Charge

Landslides

Reviewer \#1: The manuscript presents the results from structure-form-motion photogrammetry of a slope failure at the Las Cruces open-pit mine. The manuscript also contains 2D and 3D slope stability analyses performed along the slope of the mine. The manuscript has been submitted for potential publication to "Landslides" as a Recent 
Landslides article. Such articles are intended to describe the slope failure including its characteristics, the geology of the area, and the triggering mechanism along with the damages caused and any pictures, cross-sections and other relevant details regarding the failure. The manuscript focuses on the use of structure-form-motion photogrammetry and $2 \mathrm{D}$ and $3 \mathrm{D}$ slope stability analyses as opposed to the slope failure. In the Reviewer's opinion, the manuscript is its current form is not suitable for publication since it does not contain sufficient details regarding the slope failure and the information that is provided has been published in previous articles, as cited within the paper. Thus, the Reviewer recommends that the paper be declined.

The authors are provided with the following additional detailed comments regarding their manuscript:

1) The Acknowledgements section should be at the end of the manuscript as opposed to just below the abstract.

2) The second sentence in the Introduction is unclear and should be re-written in a better way.

3) All of the contents in Sections 2.1 and 2.2 appear to have been previously published in either Montero et al. (2009) and/or Cooper et al. (2011) as cited by the authors in their paper.

4) It is unclear in Line 18 on Page 4 what latter is referring to. Please clarify.

5) The contents in Section 4 should not be included within a Recent Landslides articles in "Landslides."

6) The conclusion in Lines 44 to 45 on Page 5 is not justified based on the information presented in the manuscript.

7) It is unclear how the authors established suction values of $100 \mathrm{kPa}$ and $200 \mathrm{kPa}$ in Line 5 on Page 6. The reasoning for the selection of these values in the stability analyses should be clearly explained along with their ability to represent the field conditions.

8) It is stated in Line 14 on Page 6 that pore water pressures developed as a result of rainfall. However, no details regarding the rainfall prior to the failure have been presented in the manuscript to this point.

9) The statements in Lines 56 to 58 on Page 6 are not justified based on the data presented.

10) The quality of Figures 3 and 4 requires significant improvement.

Recipients of this email are registered users within the Editorial Manager database for this journal. We will keep your information on file to use in the process of submitting, evaluating and publishing a manuscript. For more information on how we use your personal details please see our privacy policy at https://www.springernature.com/productionprivacy-policy. If you no longer wish to receive messages from this journal or you have questions regarding database management, please contact the Publication Office at the link below.

In compliance with data protection regulations, you may request that we remove your personal registration details at any time. (Use the following URL:

https://www.editorialmanager.com/lasl/login.asp?a=r). Please contact the publication office if you have any questions. 
Juan López-Vinielles ${ }^{1,2,3,}$, Pablo Ezquerro ${ }^{1,3}$, José A. Fernández-Merodo ${ }^{1,3}$, Marta Béjar-Pizarro ${ }^{1}$, Oriol Monserrat $^{4}$, Anna Barra ${ }^{4}$, Pablo Blanco ${ }^{5}$, Javier García-Robles ${ }^{5}$, Antón Filatov ${ }^{5}$, Juan C. García-Davalillo ${ }^{1}$, Roberto Sarro $^{1}$, Joaquín Mulas ${ }^{1}$, Rosa M. Mateos ${ }^{1}$, José M. Azañón ${ }^{6}$, Jorge P. Galve ${ }^{6}$, Gerardo Herrera ${ }^{1,7}$

\title{
Remote analysis of an open-pit slope failure: Las Cruces case study, Spain
}

${ }^{1}$ Geohazards InSAR Laboratory and Modeling Group (InSARlab), Geoscience Research Department, Geological Survey of Spain (IGME), Calle Alenza 1, 28003 Madrid, Spain.

${ }^{2}$ HEMAV SL, Carrer d'Esteve Terrades 1, 08860 Castelldefels, Barcelona, Spain.

${ }^{3}$ Technical University of Madrid (UPM), School of Civil Engineering (ETSI CCP), Calle Profesor Aranguren s/n, 28040 Madrid, Spain.

${ }^{4}$ Geomatics Division, Centre Tecnològic de Telecomunicacions de Catalunya (CTTC), Avinguda Carl Friedrich Gauss 7, 08860 Castelldefels, Barcelona, Spain.

${ }^{5}$ TRE ALTAMIRA SLU, Carrer de Còrsega, 381-387, E-08037 Barcelona, Spain.

${ }^{6}$ Department of Geodynamics, University of Granada, Campus Universitario Fuentenueva, 18071 Granada, Spain.

${ }^{7}$ EuroGeoSurveys: Earth Observation and Geohazards Expert Group (EOEG), Rue Joseph II 36-38, 1000 Brussels, Belgium.

Correspondence and requests for materials should be addressed to J.L.V. (email: jlvinielles@ gmail.com)

\begin{abstract}
Slope failures occur in open-pit mining areas worldwide producing considerable damage and economic losses. Identifying the triggering factors and detecting unstable slopes and precursory displacements, which can be achieved by exploiting remote sensing data, is critical to reduce their impact. Here we present a methodology that combines digital photogrammetry, satellite radar interferometry and geo-mechanical modeling, to perform remote analyses of slope instabilities in open-pit mining areas. We illustrate this approach by evaluating through back-analysis a massive landslide occurred in an active open-pit mine in southwest Spain in January 2019. Based on pre- and post-event high-resolution digital elevation models derived from digital photogrammetry, we estimate an entire sliding mass volume of around 14 million $\mathrm{m}^{3}$. Radar interferometry reveals that the line of sight accumulated displacement in the slope during the year preceding the landslide reached -5.7 and $4.6 \mathrm{~cm}$ in ascending and descending geometry respectively, showing two acceleration events clearly correlated with rainfall in descending geometry. Through $3 \mathrm{D}$ and 2D stability analyses, we confirm the location of the slope instability and explain the progressive failure mechanism. A delayed collapse was triggered by rainfall events that progressively reduced suction on the sliding materials, which was also favored by their strain-softening behavior. Finally, we discuss the potential of this methodological approach either to remotely perform post-event analyses of mining-related landslides and evaluate potential triggering factors, or to remotely identify critical slopes in mining areas and provide pre-alert warning.
\end{abstract}

\section{Keywords}

Open-pit mine, Structure-from-Motion (SfM), Satellite Radar Interferometry (InSAR), Stability Analysis, Finite Element Method (FEM), Shear Strength Reduction (SSR) 


\section{Introduction}

Mass movements and surface deformations, caused either by ground subsidence or slope instability processes, are very frequent phenomena both in abandoned and active mining areas (Bell and Donnelly 2006). In open-pit mining, ground movements potentially lead to slope failures with risks to personnel, equipment and infrastructures, disrupting mine scheduling and increasing production costs (Paradella et al. 2015). However, the absence of any failures in an open-pit mine would be a sign of over-conservative slope design (Hoek et al. 2000). Thus, conducting comprehensive slope monitoring and modeling programs is essential for the open-pit mining industry to ensure safety. The literature reports many case studies concerning the analysis of large-scale landslides in open-pit mines, whose mobilized mass volumes range from 200,000 $\mathrm{m}^{3}$ to 65 million $\mathrm{m}^{3}$. These studies focus on slope monitoring (Brawner and Stacey 1979; Pankow et al. 2014; Carlà et al. 2018), slope modeling (Voight and Kennedy 1979; Tutluoglu et al. 2011; Ozbay and Cabalar 2014) and slope stabilization (Seegmiller 1979).

In open-pit mining, slope monitoring is usually addressed using in-situ techniques such as topographic surveying (total stations/prisms, GPS, etc.) and subsurface techniques (inclinometers, extensometers, etc.) (Vaziri et al. 2010). Until the last decade, the application of remote sensing to this aim had not been extensively investigated and its use in the mining sector remains being remarkably scarce. Within this context, Structure-from-Motion (SfM) (Ullman 1979) photogrammetry and satellite Synthetic Aperture Radar Interferometry (InSAR) (Ferretti et al. 2001), represent powerful alternatives for the remote monitoring of open-pit slopes. The SfM technique enables 3D automatic reconstruction of surfaces from high-resolution imagery by applying digital photogrammetry, i.e. multi-view stereopsis algorithms that do not require background knowledge from the user (James and Robson 2012). Whereas traditional softcopy photogrammetric methods require either camera positions or the location of Ground Control Points (GCPs) to be known prior to scene reconstruction, the SfM approach requires neither of them. Using the latter, camera pose and scene geometry are reconstructed simultaneously through the automatic identification of matching features in multiple images (Westoby et al. 2012). Initial estimates of camera positions and object coordinates are refined iteratively using non-linear least-squares minimization as multiple solutions become available from the wide range of features in the image database (Snavely 2008). Over the last decade, SfM has been widely employed by the scientific community to study slope instabilities associated to different phenomena (e.g. de-Bari et al. 2011; Lucieer et al. 2014; Jordá Bordehore et al. 2017; Sarro et al. 2018; Tomás et al. 2018), including mining-related slope instabilities (Thoeni et al. 2012; Chen et al. 2015; Haas et al. 2016; Salvini et al. 2018; Xiang et al. 2018). In addition, over the last two decades, satellite InSAR has been applied to monitor mass movements over wide areas from space at sub-millimeter accuracy (Crosetto et al. 2016). Although the literature reports many case studies concerning the monitoring of mining-induced ground movements using satellite InSAR, most of them focus on ground subsidence (e.g., Carnec and Delacourt 2000; Raucoules et al. 2007; Samsonov et al. 2013; Ng et al. 2017). Whereas Groundbased SAR interferometry (GB-SAR) has shown to be an operational and consolidated technique for the monitoring of slope stability in open-pit mines (Monserrat et al. 2014), very few examples exist of the use of satellite InSAR for this purpose due to the decorrelation produced by the strong topographical variations occurring in any active open-pit mine. Detection and mapping of open-pit slope instabilities was possible in abandoned mining areas exploiting ERS and ENVISAT satellites in Spain (Herrera et al. 2010). The high spatial resolution and short acquisition frequency of TerraSAR-X satellite enabled successful monitoring of slope instabilities in an active open-pit mining area in Brazil (Paradella et al. 2015). The improved acquisition frequency of Sentinel-1 satellite mission with respect to previous C-band missions, permitted to predict a slope failure occurred in an open-pit mine in Turkey through back-analyses of InSAR and GBSAR displacement time series (Carlà et al. 2018).

On the other hand, slope stability analyses have been traditionally performed using Limit Equilibrium (LE) approaches involving methods such as the ordinary method of slices (Fellenius, Bishop simplified, Spencer, and Morgenstern-Price methods) (Duncan 2003). However, more recently, the application of advanced Finite Element (FE) modeling approaches, such as those using the Shear Strength Reduction (SSR) technique, is getting increasing attention. SSR simply reduces the soil shear strength, in terms of friction angle $\Phi$ and cohesion $c$, until collapse occurs. The resulting Safety Factor $(S F)$ is the ratio of the soil's actual shear strength to the reduced shear strength at failure. Therefore, a $S F$ greater than 1 indicates an equilibrium situation. FE combined with SSR has a number of advantages over LE. Most importantly, the critical failure surface is found automatically, i.e. no assumption needs to be made in advance about its shape or location. 
In this paper, we present a methodology that combines SfM photogrammetry, satellite InSAR and FE modeling to remotely evaluate slope instabilities in mining environments. We illustrate this approach by evaluating through back-analysis a large slope failure occurred in January 2019 at Las Cruces, an open-pit copper mine located in southwest Spain (Fig. 1).

The paper is organized as follows. First, the case study section describes the slope failure, the study area, the mining operation and the involved lithology. Then, in the methodology section, we provide a description of the methods and datasets used to obtain the results provided. Following, the photogrammetry section describes the SfM results. Thereafter, the satellite InSAR section focus on the results generated using an advanced InSAR processing chain called SqueeSAR® (Ferretti et al. 2011). Further, the correlation of the InSAR results with rainfall is evaluated, and inverse velocity plots are analyzed. At the end, the modeling section details the results of 3D and 2D stability analyses computed through a numerical modeling code called GeHoMadrid (Fernández-Merodo et al. 2014; Bru et al. 2018). Failure conditions are then determined for different geotechnical-hydrogeological scenarios through a back-analysis of the failure. Finally, potential triggering and contributing factors are discussed based on the modeling results.

\section{Case study: Las Cruces slope failure}

A massive landslide occurred in the early morning of 23 January 2019 at Las Cruces, an open-pit mine located $20 \mathrm{~km}$ north-northwest of Seville (Fig. 1). Fortunately, the failure occurred during a shift change and neither fatalities nor injuries were reported (Ecologistas en Acción Sevilla 2019). The landslide affected the north slope of the open pit, leading to the collapse of the north dump. Several pieces of mining equipment and the entrance to an investigation ramp whose construction had been completed the previous year were buried by the moving mass. Las Cruces mine is located in the southeastern part of the Iberian Pyrite Belt (IPB), which forms part of the South Portuguese Zone, the southernmost terrain of the Variscan Belt of Europe (Oliveira 1990). The region is characterized by a fairly simple stratigraphic succession that includes a 2000-m-thick basal siliciclastic sequence made up of shale and quartz arenite, which constitutes the PQ Group of Late Devonian age (Tornos et al. 2017). The transition to the overlying Volcanic Sedimentary Complex (latest Devonian to Early Carboniferous), which represents the host rock of Las Cruces deposit, is defined by a discontinuous and highly variable unit composed of mass flows, carbonate reefs, and continental sediments (Moreno et al. 1996). These volcano-sedimentary rocks constitute the Paleozoic basement, located at a depth of $150-200 \mathrm{~m}$ at the mine site. The sulfide deposit exploited in Las Cruces is located beneath Cenozoic sediments deposited over the ENE-WSW-trending Guadalquivir Basin. This basin developed during Neogene compression between Africa and Eurasia, and was later filled by Miocene-aged marine sediments (Sanz-de-Galdeano and Vera 1992). Its stratigraphic sequence starts with a few meters thick calcarenite unit, which hosts the so-called "Niebla-Posadas" aquifer (Miguélez et al. 2011), overlain by a $150 \mathrm{~m}$ thick unit of homogeneous, poorly stratified, bluish to grey, shallow marine marl, known as "Blue Marl" (Tsige et al. 1994), that increases in thickness towards southeast. Finally, Quaternary fluvial sediments overlie these Tertiary deposits.

Las Cruces mine has now been operating for nine years and the mine schedule is foreseen to run until late 2021 (First Quantum Minerals Ltd. 2015). The mining production has developed six phases and four main waste dumps (north, west, south, and in-pit backfill dumps) (Fig. 2). The monitoring system implemented in Las Cruces consists of a monitoring net integrating piezometers, inclinometers and prisms (Montero et al. 2009; Cooper et al. 2011). By the end of 2018, phase fourth was almost finished and the exposed ore from phases fifth and sixth was being mined. The exploitation consists of an open pit measuring roughly $1,500 \mathrm{~m}$ long, $900 \mathrm{~m}$ wide and $200 \mathrm{~m}$ deep. It is developed in benches $10 \mathrm{~m}$ high and $60^{\circ}$ slope gradient, except for the first top two benches, with $45^{\circ}$ slope gradient. The overall slope and interramp angles in the failure sector were $28^{\circ}$ and $32^{\circ}$, respectively.

The slopes in Las Cruces mine have been investigated by Cooper et al. (2011). The authors provide a description of the role of bedding planes and a FLAC2D-based back-analysis of an instability that occurred when the second phase was reaching its end, affecting three benches located on the north slope of the pit. In addition, Montero et al. (2009) focus on predicting the pore-water pressure drop due to the volumetric expansion associated with the excavation of the pit through a FLAC3D-based hydro-mechanical model, whose results reveal a maximum pressure drop of $864 \mathrm{kPa}$, measured by a vibrating wire piezometer located internally to the pit. In principle, the pore-water pressure drop induced by the excavation process of Las Cruces open pit allows for a steeper and more aggressive slope design (Montero et al. 2009; Cooper et al. 2011), as it produces a suction force in the impermeable layers that improves slope stability. Such suction 
was maintained in Las Cruces by means of groundwater pumping through the dewatering system required for the mine operation (Cooper et al. 2011).

Regarding lithology, Montero et al. (2009) establish the following levels from top to bottom at the mine site: (i) three levels of weathered marl, ranging from highly weathered to moderately weathered, with a total thickness of around $30 \mathrm{~m}$; (ii) four levels of fresh marl, with consistencies ranging from very hard to soft rock and a total thickness of $100 \mathrm{~m}$ roughly; (iii) one level of sandy marl, with around $5 \mathrm{~m}$ thickness; (iv) one level of sands, with thickness ranging from 0 to $15 \mathrm{~m}$; and (v) the Paleozoic bedrock. The water table is located $30 \mathrm{~m}$ below surface and permeability values range from $10^{-9}$ to $10^{-11} \mathrm{~ms}^{-1}$ (fairly impermeable) for the marls (Montero et al. 2009).

Fig. 2 shows the layout of Las Cruces, including a cross-section of the north slope displaying the lithostratigraphic sequence (adapted from Montero et al. 2009, Cooper et al. 2011 and First Quantum Minerals Ltd. 2015). Weathered marls are labelled as M1, M2 and M3, and fresh marls, as L1, L2, L3 and L4. As the embankment or barrier berms were built to a height of $25 \mathrm{~m}$ (First Quantum Minerals Ltd. 2015), we considered a height of $30 \mathrm{~m}$ for the north dump. Taking into account the presence of bedding planes dipping $3^{\circ}$ to the south within the marl layers (Cooper et al. 2011), an average dip of $3^{\circ}$ to the south was adopted for the marls and sands.

\section{Methodology}

\subsection{Structure from Motion (SfM)}

Immediately after the failure, the available literature was collected, as well as data on orthoimages, topography, geology, hydrogeology and geotechnical properties of the materials involved. Fig. 3 shows two orthoimages of the study area before and after the failure.

A post-failure orthoimage (Fig. 3b), corresponding to January 2019, was obtained through the application of SfM techniques. A set of 204 photos (resolution of 3,840 x 2,160 pixels) was processed using the software Agisoft Photoscan Pro (Agisoft LLC 2018). The photos were taken on 25 January 2019 (i.e. 2 days after the failure) from a private helicopter with a conventional digital camera for visual inspection purposes. As no camera positions were available for the images, five GCPs were extracted from a 2013 Aerial Laser Scanning (ALS) point cloud and placed on the model. The 2013 ALS point cloud was directly downloaded from Instituto Geográfico Nacional (2019). Due to the presence of the moving mass, no GCPs could be placed inside the pit. GCPs in areas not affected by the mining operation were selected for referencing only. Additionally, a post-failure DEM (Fig. 4), corresponding to January 2019, was also obtained by processing these 204 photos.

On the other hand, a pre-failure orthoimage (Figs. 2a and 3a) and a set of ten quasi-vertical single-frame aerial images ( $1 \mathrm{~m}$ resolution) covering the study area, both of them corresponding to February 2016, were downloaded from Instituto Geográfico Nacional (2019) as well. Finally, a pre-failure DEM (Figs. 5 and 6), corresponding to February 2016, was obtained by processing those ten single-frame aerial images also using the software Agisoft Photoscan Pro. Again, no camera positions were available so the GCPs used for referencing the post-failure DEM were also placed on the model, including an additional in-pit GCP placed on the bottom of the pit to ensure a reliable photogrammetric processing result in the vertical direction.

The external boundaries of the slope failure (Figs. 3 and 4) were defined by photointerpretation using the pre- and post-failure orthoimages. The source area for the initial estimation of the moving mass volume was obtained by selecting the negative elevation change values (red to yellow area in Fig. $4 \mathrm{a}$ and blue line fill pattern in Fig. 4b). The elevation change was calculated as the difference between the post- and prefailure DEMs, and the initial volume estimate was calculated as the mean elevation difference within the source area multiplied by its surface area. Then, the geometry of the basal shear plane (red dashed line in Fig. 4b) was deduced by comparing the two DEMs and taking into account the lithological profile of the open pit. The initial estimation of the overall volume of the instability was further refined by considering this basal shear plane profile. In order to do this, a smooth theoretical 3D shear surface was derived from both the basal shear plane profile and the external boundary of the failure using Inverse Distance Weighting interpolation. The source area for the refined volume estimate was delimited by selecting the pixels where the difference between the theoretical 3D shear surface and the pre-failure DEM was negative (red line fill pattern in Fig. 4b). The refined volume estimate was calculated as the mean of this differential value within the recomputed source area multiplied by its surface area. 
Ground deformation velocity maps and time series in Las Cruces were derived by processing Sentinel-1 images using the commercial SqueeSAR $®$ processing chain (https://site.tre-altamira.com/), which provides ground deformation velocities and time series over the study area. The first one aims at identifying areas affected by ground movements, whereas the second one provides information about sudden changes or accelerations in the monitoring period, which is essential to determine triggering factors through backanalysis. Moreover, the processing of Sentinel-1 images through SqueeSAR® provides a good picture of the temporal evolution of the displacements with great spatial coverage, thanks to the short revisit time of the satellite (six days). For this study, both ascending and descending data were processed covering the period from 4 January 2018 to 17 January 2019. The results were obtained by processing 63 and 62 Sentinel1 ascending and descending images (spatial resolution of $3 \times 14 \mathrm{~m}$ ), respectively. Thus, ground deformation velocity maps (Fig. 5) and time series (Fig. 6) were calculated in the area of the mine for the year prior to the failure. Further, the correlation of the deformation time series with rainfall was analyzed taking into account daily precipitation records from Agencia Estatal de Meteorología (2019).

Finally, inverse velocity calculations (Fig. 7) were conducted using the methodology proposed in Dick et al. (2015). According to the inverse velocity method, the time of failure for an instability in accelerating creep conditions corresponds to the point of intersection on the abscissa of the extrapolated trend in a 1/velocity vs. time plot (Fukuzono 1985; Voight 1988, 1989; Petley et al. 2002; Crosta and Agliardi 2003; Sornette et al. 2004; Carlà et al. 2018). In this study, noise of radar time series was filtered using a five-day moving mean and inverse velocity values over $\pm 200 \mathrm{~d} / \mathrm{cm}$ were deleted to improve de visualization. Inverse velocity was calculated using the following equation:

$$
i v_{i}=\frac{t_{i}-t_{i-1}}{d_{i}-d_{i-1}}
$$

Where $i v_{i}$ is the inverse velocity at the date of interest $t_{i} ; t_{i-1}$ is the previous date; $d_{i}$ is the accumulated displacement at the date of interest $t_{i}$; and $d_{i-1}$ is the accumulated displacement at the previous date $t_{i-1}$.

\subsection{Numerical modeling}

Stability analyses were performed through the application of a FE modeling approach using the SSR technique jointly with the elastoplastic Mohr-Coulomb failure criterion (Zienkiewicz et al. 1975; Dawson et al. 1999). The approach was implemented through the so-called GeHoMadrid code, a hydro-mechanical FE modeling program in which failure is defined using a non-convergence criterion of the Newton-Raphson non-linear algorithm, with a normalized unbalanced force limit of $10^{-4}$ (Fernández-Merodo et al. 2014; Bru et al. 2018). The only purpose of the stability analyses, performed using the SfM-derived pre-event DEM, was to discuss potential triggering and contributing factors influencing the failure. The analyses were addressed in two steps. First, a simplified 3D stability analysis over the open pit was performed in order to locate the most critical slope due solely to the geometry of the open pit. Secondly, detailed 2D slope stability analyses were computed over the recognized critical slope, taking into account precise lithology and different hypotheses of shear strength parameters (peak and mobilized conditions) and water table depths.

The simplified 3D stability analysis was performed as follows. For the geometry of the study area, we used the pre-failure DEM considering a box of size 1,860 m x 2,200 m centering the open pit (white dashed box in Fig. 2). For the materials, a unique homogeneous material was considered, corresponding to the Blue Marls. Averaged material properties (unit weight $Y=15 \mathrm{kNm}^{-3}, \Phi=20^{\circ}, c=250 \mathrm{kPa}$,) were adopted. For the boundary conditions, displacements were fixed in the bottom plane, located $\sim 300 \mathrm{~m}$ below the surface. Perpendicular displacements were also fixed in the side planes and a pore-water pressure value of $0 \mathrm{kPa}$ was prescribed on the surface (saturated condition). For the applied external load, only gravity force was contemplated. The 3D finite element mesh, composed by 227,202 nodes and 149,325 quadratic tetrahedral elements (10 nodes per element), and the adopted hydrostatic pore pressure contours are depicted in Fig. 8. The performed 3D stability analysis is shown in Fig. 9.

Thereafter, detailed 2D stability analyses were performed over the recognized critical section, coincident with the north slope, considering plane-strain conditions. Elevation values from the pre-failure DEM were 
also used for the geometry of the north slope. Precise lithology, described in previous publications was taken into account. The geo-mechanical properties of the thirteen materials considered, are shown in Table 1 (adapted from Montero et al. 2009, Boza 2014 and First Quantum Minerals Ltd. 2015). The properties of the failure surface in residual conditions are also shown (Gens and Alonso 2006; Cooper et al. 2011). Associated plasticity was adopted. Regarding constrains, displacements were fixed in the bottom boundary, located $\sim 250 \mathrm{~m}$ below the surface, and perpendicular displacements were fixed in the side boundaries. For the applied external load, only gravity force was contemplated. Then, we prescribed three different porewater pressure values on the surface. Firstly, a stability analysis of the north slope was performed in peak conditions, i.e. using peak shear strength parameters, prescribing a hydrostatic pore-water pressure of -300 $\mathrm{kPa}$ on the surface. Secondly, a stability analysis was computed in peak conditions prescribing a pore-water pressure of $-150 \mathrm{kPa}$ on the surface. The soil water retention curve (SWRC) of the Blue Marls provided by Boza (2014) (Fig. 10) was taken into account for these two non-saturated cases. Thirdly, a stability analysis was computed in peak conditions considering no suction, i.e. prescribing a pore-water hydrostatic pressure of $0 \mathrm{kPa}$ on the surface (saturated condition). For the shake of simplification, the pore pressure distributions considered for the non-saturated cases do not take into account the suction resulting from the excavation process of the open pit but from the position of the water table. On the other hand, the saturated case represents a simplification of the field conditions, as the Blue Marls can hardly reach total saturation (Boza 2014). The reason for the selection of these three suction values on the surface was to evaluate slope stability in the theoretical actual scenario (300 kPa suction), in the worst-case scenario ( $0 \mathrm{kPa}$ suction), and in an intermediate scenario (150 kPa suction). Note that the actual depth of the "Niebla-Posadas" aquifer at the mine site is $30 \mathrm{~m}$ (Montero et al. 2009), and prescribing a $-300 \mathrm{kPa}$ pore pressure on the surface results in a hydrostatic pore pressure distribution equivalent to that produced by a $30-\mathrm{m}$-deep water table. Moreover, we consider that $300 \mathrm{kPa}$ represents a rather conservative suction value since the suction potential corresponding to the natural humidity of the Blue Marl (around $25 \%$ according to Boza 2014) is much higher according to its SWRC. Using the SWRC in Fig. 10, a degree of saturation $S_{r}$ of $86 \%$, equivalent to a natural humidity of $25 \%$, results in suctions of around $1 \mathrm{MPa}$. Finally, mobilized friction angle $\left(\Phi_{m}\right)$ values were calculated through back-analysis for the basal shear plane in Fig. 4b (with a constant residual cohesion of $10 \mathrm{KPa}$ ) in order to get a $S F$ equal 1 for each pore pressure scenario. Note that, when conducting stability analyses to determine mobilized friction angles, the actual position of the failure surface must be known. The finite element mesh, composed by 8,493 nodes and 4,122 quadratic triangular elements (6 nodes per element) is shown in Fig. 11. For the stability analysis in peak conditions, thirteen materials were considered (Fig. 11a). For the back-analysis in mobilized conditions, an additional unit representing the basal shear plane was introduced (Fig. 11b), corresponding to the primary failure surface deducted from the SfM analysis. The three adopted hydrostatic pore pressure contours and the two resulting saturation contours are also depicted. Three meshes were evaluated in terms of accuracy and consumed CPU time. Fig. 12 shows the influence of the mesh size (Safety Factor $S F$ and consumed CPU time vs. number of degrees of freedom d.o.f.) on the stability analysis conducted with a suction of $150 \mathrm{kPa}$ and in peak conditions. In order to achieve a good compromise between accuracy and consumed CPU time, MESH 2 was selected for all the analyses (Fig. 11). Finer meshes such as MESH 3 did not improve the results substantially. The performed 2D stability analyses are shown in Fig. 13.

\section{Results}

\subsection{Remote-sensed topography and geomorphic mapping}

The post-failure orthoimage (Fig. 3b) was used to conduct, along with the pre- and post-failure DEMs, a detailed geomorphic analysis of the landslide (Fig. 4). We classify the slope failure as a complex movement (Varnes 1978) with a well-defined exposed shear plane clearly present in the post-failure DEM (Fig. 4a), which suggests a primary failure initiated somewhere near the north dump barrier berm triggering subsequent failures towards the dump. The entire moving mass consists of two distinct parts: (i) an upper part with the typical features of a rotational landslide such as head scarp, secondary scarps and sagged crown; and (ii) a mudflow-earthflow lower part, with debris on the frontal section. The external boundaries of the slope failure (red lines in Figs. 3 and 4a) were used to determine the landslide surface area $(785,000$ $\mathrm{m}^{2}$ ). Then, the obtained pre- and post-failure DEMs were used to estimate failure volumes. The post-failure DEM yielded $0.97 \mathrm{~m}$ resolution and $0.86 \mathrm{~m}$ total error, whereas the pre-failure DEM resulted in $1.65 \mathrm{~m}$ resolution and $1.3 \mathrm{~m}$ total error. The difference between the two DEMs yielded a volume of 11.4 million $\mathrm{m}^{3}$, with a mean height difference of $31.4 \mathrm{~m}$ and a source area of $364,000 \mathrm{~m}^{2}$. Based on the difference 
between the theoretical 3D shear surface and the pre-failure DEM, the estimation of the overall volume of the landslide resulted in 14 million $\mathrm{m}^{3}$, which is $\sim 1.2$ times the initial estimates. On the other hand, the recalculated source area was $3 \%$ larger $\left(375,000 \mathrm{~m}^{2}\right)$ and the average sliding surface depth, $6 \mathrm{~m}$ deeper (37.4 m).

\subsection{Ground deformation maps and time series analysis}

Following the SfM analysis, we obtained line of sight (LOS) velocity maps (Fig. 5). The results in ascending geometry (Fig. 5a) contain 18,814 measurement points (MPs), showing only negative LOS velocities (movement away from the satellite) over the study area. The south dump exhibits the maximum negative velocity, with a value of $-20.4 \mathrm{~cm} /$ year, whereas the north slope shows a maximum velocity of -13.2 $\mathrm{cm} /$ year. The map in descending geometry (Fig. 5b) contains 19,475 MPs and shows several areas moving away from the satellite as well, corresponding to waste dumps distributed around the open pit (Fig. 2). Once more, the south dump exhibits the maximum negative velocity, with a value of $-23.0 \mathrm{~cm} / \mathrm{year}$, but in contrast to the ascending results, the map in descending geometry shows positive LOS velocities (movement towards the satellite) over the north slope, with a maximum velocity of $7.7 \mathrm{~cm} /$ year. The opposite direction of the movements measured along both satellite LOSs over the north slope indicates that the actual displacements have a strong horizontal component. Note that even though LOS velocities are higher in the south dump, it does not necessarily imply that real deformation velocities are lower in the north slope. Since the velocities are measured along the satellite LOS, different percentages of the real displacements are measured depending on the main direction of the movement with respect to the LOS. In the north slope, real displacements have a strong horizontal component, which is consistent with the direction of the slope, oriented southeast with a slope gradient of around $30^{\circ}$. For this reason, the LOS vector partially detects displacement over this slope both in ascending and descending geometry. In the south dump, a higher percentage of the real displacements is measured due to the dominantly vertical component of the actual displacements (related most probably to consolidation processes), consistent with the relatively flat geometry of the dump.

Thereafter, we conducted a zonal analysis from the resulting displacement time series both in ascending and descending geometry (Fig. 6). Five areas were selected for the analysis (processing plant, north slope, south dump, north dump 1 and north dump 2 in Fig. 6a), whose mean deformation velocities are shown in Fig. 6c. As shown in Fig. 6b, accumulated displacements over the north slope reach -5.7 and $4.6 \mathrm{~cm}$ in ascending and descending geometry, respectively, from January 2018 to January 2019. In ascending geometry, the trend shows an acceleration in mid-November 2018 and a deceleration in early January 2019, whereas in descending geometry, it shows two acceleration events in mid-January 2018 and early October 2018 and two deceleration events in late March 2018 and mid-December 2018. All other areas exhibit negative accumulated displacements both in ascending and descending geometry, except for the processing plant (Fig. 6d), which shows stable trends for comparison. The south dump (Fig. 6e) shows an acceleration event from early March 2018 to late May 2018, a deceleration event from early September 2018 to late October 2018 and a linear trend in between. These acceleration and deceleration events correspond most likely to the initial and final stages, respectively, of the consolidation process induced by the enlargement of the dump. Finally, the north dumps (Figs. $6 \mathrm{f}$ and $6 \mathrm{~g}$ ) show near linear settlement trends, related most likely to the consolidation process as well, that resemble that of the north slope in ascending geometry (Pearson correlation coefficient between 99 and 100\%), indicating a potential relationship between the deformation processes affecting both the north slope and the north dumps. The events observed over the north slope in descending geometry, moreover, are well correlated with accumulated rainfall (Pearson coefficient 99\%), coinciding with two rainfall episodes from early January to late April 2018 and from early September to late December 2018 (Agencia Estatal de Meteorología 2019). On the contrary, the acceleration event revealed by the ascending results in the north slope, slightly delayed with respect to the last acceleration event observed in descending geometry, show a slightly worse correlation with rainfall (Pearson coefficient 90\%). To conclude, in the south and north dumps, the results show an even lower correlation with rainfall (Pearson coefficient between 64 and 83\%).

Finally, an analysis of the displacement time series both in ascending and descending geometry using the inverse velocity approach was undertaken (Fig. 7). The inverse velocity plots show noisy but stable trends in the south and north dumps (Figs. 7d, 7e and 7f), although this also applies to the plot corresponding to the north slope in ascending geometry (dark grey line in Fig. 7a). Contrarily, in descending geometry, the inverse velocity plot of the north slope shows a distinct non-linear trend (light grey line in Fig. 7a). According to the definition of acceleration event, the two accelerations observed in the north slope in descending geometry, as well as the acceleration observed in the north slope in ascending geometry, can be 
classified as temporary accelerations. Therefore, in this case, predictions of the time of failure using the inverse velocity method, which assumes that the slope displaces at an accelerating rate up to the point of failure, must be dealt with carefully. Considering the period from 1 September to 31 December 2018, i.e. the period corresponding to the rainfall episode prior to the failure, linear regressions of the inverse velocity plots of the north slope in ascending and descending geometry (black dashed lines in Figs. 7b and 7c) are of low quality ( $\mathrm{R}^{2}$ values of 0.03 and 0.28 respectively). However, linear regression of the inverse velocity plot of the north slope in ascending geometry provides, in retrospect, an excellent prediction of the time of failure $\left(\mathrm{R}^{2}=0.84\right.$ ) when considering the period from 7 October to 31 December 2018 (red dashed line in Fig. 7b). In any case, this prediction only makes sense in the context of a back-analysis, as there also was a temporary acceleration in mid-January 2018 over the north slope according to the descending results, and no failure was triggered.

\subsection{Stability analysis}

The results of the 3D stability analysis are illustrated in Fig. 9. The 3D stability analysis results in a $S F$ equal to 1.20 , which indicates that all the open-pit slopes are stable for that particular configuration. However, the computed critical slope is located in the northwest side of the open pit, i.e. in the north slope. The computed failure source area (light blue polygon in Fig. 9a) is estimated at 314,000 m².

The results of the 2D stability analysis are shown in Fig. 13. For the best-case scenario, i.e. $-300 \mathrm{kPa}$ pore pressure on the surface ( $1^{\text {st }}$ row in Fig. 13), the computed $S F$ is equal to 1.28. In the intermediate scenario, i.e. $-150 \mathrm{kPa}$ pore pressure on the surface ( ${ }^{\text {nd }}$ row in Fig. 13 ), the computed $S F$ is equal to 1.14. Finally, in the worst-case scenario, i.e. $0 \mathrm{kPa}$ pore pressure on the surface ( $3^{\text {rd }}$ row in Fig. 13), the computed $S F$ is equal to 1.00 . On the other hand, mobilized friction angle $\left(\Phi_{m}\right)$ values calculated using the mesh shown in Fig. $11 \mathrm{~b}$, result in $18^{\circ}, 21^{\circ}$ and $29^{\circ}$ for the best-case, intermediate and worst-case scenarios, respectively.

Therefore, whereas the two suction cases in peak conditions indicate stable configurations $(S F>1)$, the saturated case in peak conditions indicate a limit equilibrium situation $(S F=1)$. These results demonstrate that pore-water pressure has a very strong influence on the slope stability. The greater the suction the more stable the slope. In the same way that positive pore-water pressures (e.g. due to rainfalls) decrease the effective stress and thereby decrease the strength, negative pore-water pressures (suction) increase the effective stress and in turn increase the strength. In addition, it can be observed in all the 2D stability analyses in peak conditions, in which no assumption is made in advance about the failure surface shape or location, that the computed displacement contours (all rows in Fig. 13a) reveal a failure mechanism equivalent to that deduced from our SfM analysis (Fig. 4b).

\section{Discussion and conclusions}

This study, concerned with the January 2019 landslide triggered at Las Cruces open-pit mine, highlights the potential of conducting remote analyses of slope instabilities in open-pit mining areas combining SfM photogrammetry, satellite InSAR and FE modeling. The methodology, relying exclusively on the exploitation of remote sensed and published data, has demonstrated to be useful to analyze geomorphic features, failure volumes, source areas, precursory displacements, accelerations related to rainfall, triggering factors and failure mechanisms. Regarding its limitations, the two main drawbacks of this methodology are related both to the uncertainty associated to the available data, which can only be solved using in-situ data for validation (surveying data, borehole data, inclinometers, piezometers, etc.), and to the data availability itself. For that reason, the purpose of the stability analyses presented herein is essentially to discuss potential triggering and contributing factors, rather than to accurately quantify failure conditions.

A landslide source area of $375,000 \mathrm{~m}^{2}$ and a failure volume of 14 million $\mathrm{m}^{3}$ have been estimated using $\mathrm{SfM}$ techniques. The location and extent of the landslide source area computed through the 3D stability analysis $\left(314,000 \mathrm{~m}^{2}\right)$ coincide fairly well with the SfM estimates. Both the SfM- and the modeling-derived results have been obtained using a pre-event DEM from 2016 (obtained through the application of SfM techniques), which in spite of not representing exhaustively the actual 2019 pre-event geometry, was considered appropriate for the analysis of Las Cruces north slope as no substantial topographical variations were observed in that slope between 2016 and 2019.

InSAR results indicate the presence of sub-decimeter rainfall-correlated precursory displacements with a clear horizontal component on the north slope the year prior to the failure. Due to the temporary nature of 
the observed accelerations, predictions of the time of failure using the inverse velocity method provided no conclusive results. In any case, an excellent prediction of the time of failure $\left(\mathrm{R}^{2}=0.84\right)$ is obtained in retrospect in ascending geometry when considering the period from 7 October to 31 December 2018.

Regarding the FE modelling results, a comparison between the 3D and 2D stability analyses can be made for the third hydraulic scenario, i.e. when materials are fully saturated ( $0 \mathrm{kPa}$ pore pressure on the surface) and in peak conditions. SFs equal to 1.20 and 1.00 have been computed for the 3D and 2D models respectively. This result, which is in agreement with previous works confirming that $S F_{3 D}>S F_{2 D}$ (Duncan 2003), is also explained by the addition of detailed lithostratigraphic geometry to the 2D model. A sand layer dipping towards the slope and near its toe, with weak resistance properties and low cohesion, may have had a key influence on the reported failure event. Precisely, it can be observed in all rows in Fig. 13b, that plastic strain initiates in this material and progresses until reaching the contact between shales and tuffs. Moreover, the presence of bedding planes dipping towards the slope (Cooper et al. 2011), which would contribute to create a more unstable modeling scenario, has not been considered in the present analysis. Anyway, the computed failure mechanisms in 3D and 2D are similar (Figs. 9 and 13), although the displacement contours in the three $2 \mathrm{D}$ cases in peak conditions show a slightly different geometry.

Results of the 2D stability analyses show that pore-water pressure has a very strong influence on the slope stability. In Las Cruces, suction has developed as a consequence of the substantial pore pressure drop in the impermeable marl caused by the undrained unload produced by the excavation process of the 200-m-deep open pit, adding strength to the soil by increasing the effective stress. Thus, suction allows for a more aggressive and economical slope design (Montero et al. 2009). Hence, and considering the correlation between the accumulated displacements over the north slope in descending geometry and the accumulated rainfall, the most probable triggering factor seems to be a loss of such suction resulting from a pore-water pressure increase driven by rainfall. Given the immediate response of the slope displacement to rainfall, a pore pressure increase produced by persistent water leakage from the aquifer to the marls seems to be more unlikely, especially considering the rather low permeability of the marls. The accumulated rainfall in the year preceding the landslide $(600 \mathrm{~mm})$, which is within the expected range for the region $(539 \mathrm{~mm}$ in the city of Seville), was mainly produced by two rainfall events from early January to late April 2018 and from early September to late December 2018 (Agencia Estatal de Meteorología 2019). To conclude, other contributing factor further explaining the progressive failure mechanism is the strain-softening behavior of the marls. This strain-softening behavior, which has the effect of progressively decreasing the shear strength parameters of the marls consistently with the shear strain increment, would be in consonance with the accumulated displacements observed in our InSAR data. Moreover, mechanical strain-softening behavior of the Blue Marls led to progressive failure of Aznalcóllar dam foundation in April 1998 (Alonso and Gens 2006; Gens and Alonso 2006), which is located at a $10 \mathrm{~km}$ distance (Fig. 1). In that case study, failure was calculated with no cohesion and an average friction angle of the sliding basal plane of $17-18^{\circ}$, which was between the average peak $\left(\Phi_{p}=24.1^{\circ}\right)$ and residual $\left(\Phi_{r}=11^{\circ}\right)$ friction angles measured in direct shear tests. In Las Cruces, as revealed by the stability analyses performed to determine the mobilized friction angle $\Phi_{m}$ for each pore pressure scenario, an average friction angle of the basal shear plane of $18^{\circ}$ (and a residual cohesion of $10 \mathrm{KPa})$ leads to failure conditions $(S F=1.00)$ in the best-case scenario $(-300 \mathrm{kPa}$ pore pressure on the surface). In the intermediate scenario ( $-150 \mathrm{kPa}$ pore pressure on the surface), an average friction angle of $21^{\circ}$ (and a residual cohesion of $10 \mathrm{KPa}$ ) is enough to reach failure $(S F=1.00)$. Moreover, the failure mechanism revealed by the displacement contours computed in this case is essentially identical to that deduced from our SfM analysis, in which both a primary and a secondary failure are present. Finally, in the worst-case scenario ( $0 \mathrm{kPa}$ pore pressure on the surface), an average friction angle of $29^{\circ}$ (and a residual cohesion of $10 \mathrm{KPa})$ leads to failure $(S F=1.00)$.

Therefore, according to our stability analyses, the failure would be explained by an average friction angle of the basal shear plane between $18^{\circ}$ and $21^{\circ}$ (and a residual cohesion of $10 \mathrm{KPa}$ ), and pore pressure on the surface between $300 \mathrm{kPa}$ and $150 \mathrm{kPa}$. To confirm these plausible hypotheses, the significance of the proposed progressive failure and delayed collapse could be proven trough a real time-dependent model taking into account the excavation process history. Such kind of analysis, out of the scope of this paper, has been successfully achieved in the past for progressive failure in cut slopes in stiff clays, explaining the delayed collapse of railways and motorways cutting slopes (Potts et al. 1997). Our methodology, even if characterized by certain degree of uncertainty associated to the simplifications intrinsic to the geomechanical modeling, provides a new contribution in the application of remote sensing for the monitoring and modeling of slope failures in open-pit mines in cases where data availability is limited. Even though 
here we only describe the capabilities of our methodology to perform post-event back-analyses of miningrelated landslides, similar analyses could be conducted to remotely identify unstable slopes and provide pre-alert warning to support the design of prevention and mitigation measures in open-pit mines.

\section{References}

Agencia Estatal de Meteorología (2019) AEMET OpenData. https://opendata.aemet.es/centrodedescargas/inicio. Accessed 20 Feb 2019

Agisoft LLC (2018) Agisoft PhotoScan Professional (Version 1.2.6)

Alonso EE, Gens A (2006) Aznalcóllar dam failure. Part 1: Field observations and material properties. Geotechnique 56:165-183. https://doi.org/10.1680/geot.2006.56.3.165

Bell FG, Donnelly LJ (2006) Mining and its impact on the environment. Taylor \& Francis

Boza M (2014) Comportamiento volumétrico de la marga azul del Guadalquivir ante los cambios de succión. Dissertation, University of Sevilla

Brawner CO, Stacey PF (1979) Hogarth pit slope failure, Ontario, Canada. Dev Geotech Eng 14:691-707. https://doi.org/10.1016/B978-0-444-41508-0.50029-6

Bru G, Fernández-Merodo JA, García-Davalillo JC, Herrera G, Fernández J (2018) Site scale modeling of slow-moving landslides, a 3d viscoplastic finite element modeling approach. Landslides 15:257272. https://doi.org/10.1007/s10346-017-0867-y

Carlà T, Farina P, Intrieri E, Ketizmen H, Casagli N (2018) Integration of ground-based radar and satellite InSAR data for the analysis of an unexpected slope failure in an open-pit mine. Eng Geol 235:39-52. https://doi.org/10.1016/j.enggeo.2018.01.021

Carnec C, Delacourt C (2000) Three years of mining subsidence monitored by SAR interferometry, near Gardanne, France. J Appl Geophys 43:43-54

Chen J, Li K, Chang KJ, Sofia G, Tarolli P (2015) Open-pit mining geomorphic feature characterisation. Int J Appl Earth Obs Geoinf 42:76-86. https://doi.org/10.1016/j.jag.2015.05.001

Cooper S, Perez C, Vega L, Galera JM, Pozo V (2011) The Role of Bedding Planes in Guadalquivir Blue Marls on the Slope Stability in Cobre Las Cruces Open Pit. In: Proceedings of the International Symposium on Rock Slope Stability in Open Pit Mining and Civil Engineering, Vancouver. pp 116

Crosetto M, Monserrat O, Cuevas-González M, Devanthéry N, Crippa B (2016) Persistent Scatterer Interferometry: A review. ISPRS J Photogramm Remote Sens 115:78-89. https://doi.org/10.1016/j.isprsjprs.2015.10.011

Crosta GB, Agliardi F (2003) Failure forecast for large rock slides by surface displacement measurements. Can Geotech J 40:176-191. https://doi.org/10.1139/t02-085

Dawson EM, Roth WH, Drescher A (1999) Slope stability analysis by strength reduction. Geotechnique 49:835-840. https://doi.org/10.1680/geot.1999.49.6.835

de-Bari C, Lapenna V, Perrone A, Puglisi C, Sdao F (2011) Digital photogrammetric analysis and electrical resistivity tomography for investigating the Picerno landslide (Basilicata region, southern Italy). Geomorphology 133:34-46. https://doi.org/10.1016/j.geomorph.2011.06.013

Dick GJ, Eberhardt E, Cabrejo-Liévano AG, Stead D, Rose ND (2015) Development of an early-warning time-of-failure analysis methodology for open-pit mine slopes utilizing ground-based slope stability radar monitoring data. Can Geotech J 52:515-529. https://doi.org/10.1139/cgj-2014-0028

Duncan JM (2003) State of the art: Limit equilibrium and finite-element analysis of slopes. J Geotech Eng 122:577-596. https://doi.org/10.1061/(asce)0733-9410(1996)122:7(577)

Ecologistas en Acción Sevilla (2019) Denuncia del nuevo derrumbe de la Mina Cobre las Cruces. https://www.ecologistasenaccion.org/113928/denuncia-del-nuevo-derrumbe-de-la-mina-cobre-lascruces/. Accessed 20 Feb 2019

Fernández-Merodo JA, García-Davalillo JC, Herrera G, Mira P, Pastor M (2014) 2D viscoplastic finite element modelling of slow landslides: The Portalet case study (Spain). Landslides 11:29-42. https://doi.org/10.1007/s10346-012-0370-4

Ferretti A, Fumagalli A, Novali F, Prati C, Rocca F, Rucci A (2011) A New Algorithm for Processing Interferometric Data-Stacks: SqueeSAR. IEEE Trans Geosci Remote Sens 49:3460-3470

Ferretti A, Prati C, Rocca F (2001) Permanent scatterers in SAR interferometry. IEEE Trans Geosci Remote Sens 39:8-20. https://doi.org/10.1109/36.898661

First Quantum Minerals Ltd. (2015) Cobre Las Cruces Operation Andalucía, Spain NI 43-101 Technical Report. https://miningdataonline.com/reports/Cobre Las Cruces_06302015_Technical report.pdf. Accessed 20 Feb 2019

Fukuzono T (1985) A New Method for Predicting the Failure Time of a Slope. In: Proceedongs of the IVth International Conference and Field Workshop on Landslides, Tokyo. pp 145-150 
Gens A, Alonso EE (2006) Aznalcóllar dam failure. Part 2: Stability conditions and failure mechanism. Geotechnique 56:185-201. https://doi.org/10.1680/geot.2006.56.3.185

Haas F, Hilger L, Neugirg F, Umstädter K, Breitung C, Fischer P, Hilger P, Heckmann T, Dusik J, Kaiser A, Schmidt J, Della Seta M, Rosenkranz R, Becht M (2016) Quantification and analysis of geomorphic processes on a recultivated iron ore mine on the Italian island of Elba using long-term ground-based lidar and photogrammetric SfM data by a UAV. Nat Hazards Earth Syst Sci 16:12691288. https://doi.org/10.5194/nhess-16-1269-2016

Herrera G, Tomás R, Vicente F, Lopez-Sanchez JM, Mallorquí JJ, Mulas J (2010) Mapping ground movements in open pit mining areas using differential SAR interferometry. Int J Rock Mech Min Sci 47:1114-1125. https://doi.org/10.1016/j.ijrmms.2010.07.006

Hoek E, Read J, Karzulovic A, Chen ZY (2000) Rock slopes in civil and mining engineering. In: ISRM International Symposium. International Society for Rock Mechanics and Rock Engineering.

Instituto Geográfico Nacional (2019) Centro de Descargas del CNIG. http://centrodedescargas.cnig.es/CentroDescargas/index.jsp. Accessed 20 Feb 2019

Instituto Geológico y Minero de España (2008) GEODE - Zona Z2600 (Cuenca del Guadalquivir y Cuencas Béticas Postorogénicas, Subbético, Cuenca de Gibraltar). http://info.igme.es/cartografiadigital/geologica/geodezona.aspx?intranet=false \&Id=Z2600. Accessed 20 Feb 2019

James MR, Robson S (2012) Straightforward reconstruction of 3D surfaces and topography with a camera: Accuracy and geoscience application. J Geophys Res Earth Surf 117:1-17. https://doi.org/10.1029/2011JF002289

Jordá Bordehore L, Riquelme A, Cano M, Tomás R (2017) Comparing manual and remote sensing field discontinuity collection used in kinematic stability assessment of failed rock slopes. Int J Rock Mech Min Sci 97:24-32. https://doi.org/10.1016/j.ijrmms.2017.06.004

Lucieer A, Jong SM d., Turner D (2014) Mapping landslide displacements using Structure from Motion (SfM) and image correlation of multi-temporal UAV photography. Prog Phys Geogr 38:97-116. https://doi.org/10.1177/0309133313515293

Miguélez NG, Arroyo FT, Velasco F, Videira JC (2011) Geology and Cu Isotope Geochemistry of the Las Cruces Deposit (SW Spain). http://www.ehu.eus/sem/macla_pdf/macla15/Macla15_131.pdf. Accessed 20 Feb 2019

Monserrat O, Crosetto M, Luzi G (2014) A review of ground-based SAR interferometry for deformation measurement. ISPRS J Photogramm Remote Sens 93:40-48. https://doi.org/10.1016/j.isprsjprs.2014.04.001

Montero J, Perez C, Vega L, Varona P (2009) Coupled hydromechanical analysis of Cobre Las Cruces open pit. In: Proceedings Slope Stability, Santiago Chile. pp 1-9

Moreno C, Sierra S, Sáez R (1996) Evidence for catastrophism at the Famennian-Dinantian boundary in the Iberian Pyrite Belt. In: Special Publications. Geological Society of London, pp 153-162

Ng AHM, Ge L, Du Z, Wang S, Ma C (2017) Satellite radar interferometry for monitoring subsidence induced by longwall mining activity using Radarsat-2, Sentinel-1 and ALOS-2 data. Int J Appl Earth Obs Geoinf 61:92-103. https://doi.org/10.1016/j.jag.2017.05.009

Oliveira JT (1990) Stratigraphy and Synsedimentary Tectonism. In: Pre-Mesozoic Geology of Iberia. pp 334-347

Ozbay A, Cabalar AF (2014) FEM and LEM stability analyses of the fatal landslides at Çöllolar open-cast lignite mine in Elbistan, Turkey. Landslides 12:155-163. https://doi.org/10.1007/s10346-014-05372

Pankow KL, Moore JR, Mark Hale J, Koper KD, Kubacki T, Whidden KM, McCarter MK (2014) Massive landslide at Utah copper mine generates wealth of geophysical data. GSA Today 24:4-9. https://doi.org/10.1130/GSATG191A.1

Paradella WR, Ferretti A, Mura JC, Colombo D, Gama FF, Tamburini A, Santos AR, Novali F, Galo M, Camargo PO, Silva AQ, Silva GG, Silva A, Gomes LL (2015) Mapping surface deformation in open pit iron mines of Carajás Province (Amazon Region) using an integrated SAR analysis. Eng Geol 193:61-78. https://doi.org/10.1016/j.enggeo.2015.04.015

Petley DN, Bulmer MH, Murphy W (2002) Patterns of movement in rotational and translational landslides. Geology 30:719-722. https://doi.org/10.1130/00917613(2002)030<0719:POMIRA>2.0.CO;2

Potts DM, Kovacevlc N, Vaughan PR (1997) Delayed collapse of cut slopes in stiff clay. Geotechnique 47:953-982. https://doi.org/10.1680/geot.1997.47.5.953

Raucoules D, Colesanti C, Carnec C (2007) Use of SAR interferometry for detecting and assessing ground subsidence. Comptes Rendus - Geosci 339:289-302. https://doi.org/10.1016/j.crte.2007.02.002 
Salvini R, Mastrorocco G, Esposito G, Di Bartolo S, Coggan J, Vanneschi C (2018) Use of a remotely piloted aircraft system for hazard assessment in a rocky mining area (Lucca, Italy). Nat Hazards Earth Syst Sci 18:287-302. https://doi.org/10.5194/nhess-18-287-2018

Samsonov S, d'Oreye N, Smets B (2013) Ground deformation associated with post-mining activity at the French-German border revealed by novel InSAR time series method. Int J Appl Earth Obs Geoinf 23:142-154. https://doi.org/10.1016/j.jag.2012.12.008

Sanz-de-Galdeano C, Vera JA (1992) Stratigraphic record and palaeogeographical context of the Neogene basins in the Betic Cordillera, Spain. Basin Res 4:21-36. https://doi.org/10.1111/j.13652117.1992.tb00040.x

Sarro R, Riquelme A, García-Davalillo JC, Mateos RM, Tomás R, Pastor JL, Cano M, Herrera G (2018) Rockfall simulation based on UAV photogrammetry data obtained during an emergency declaration: Application at a cultural heritage site. Remote Sens 10:1-20. https://doi.org/10.3390/rs10121923

Seegmiller BL (1979) Twin buttes pit slope failure, Arizona, U.S.A. Dev Geotech Eng 14:651-666. https://doi.org/10.1016/B978-0-444-41508-0.50027-2

Snavely KN (2008) Scene Reconstruction and Visualization from Internet Photo Collections. Dissertation, University of Washington

Sornette D, Helmstetter A, Andersen J V., Gluzman S, Grasso JR, Pisarenko V (2004) Towards landslide predictions: Two case studies. Phys A Stat Mech its Appl 338:605-632. https://doi.org/10.1016/j.physa.2004.02.065

Thoeni K, Irschara A, Giacomini A (2012) Efficient Photogrammetric Reconstruction of Highwalls in Open Pit Coal Mines. In: 16th Australasian Remote Sensing and Photogrammetry Conference. pp 85-90

Tomás R, Abellán A, Cano M, Riquelme A, Tenza-Abril AJ, Baeza-Brotons F, Saval JM, Jaboyedoff M (2018) A multidisciplinary approach for the investigation of a rock spreading on an urban slope. Landslides 15:199-217. https://doi.org/10.1007/s10346-017-0865-0

Tornos F, Velasco F, Slack JF, Delgado A, Gomez-Miguelez N, Escobar JM, Gomez C (2017) The highgrade Las Cruces copper deposit, Spain: a product of secondary enrichment in an evolving basin. Miner Depos 52:1-34. https://doi.org/10.1007/s00126-016-0650-3

Tsige M, González de Vallejo L, Doval M, Barba C (1994) Microfabric of Guadalquivir "Blue Marls" and its engineering geological significance. In: International congress. International Association of Engineering Geology. pp 659-665

Tutluoglu L, Ferid Öge I, Karpuz C (2011) Two and three dimensional analysis of a slope failure in a lignite mine. Comput Geosci 37:232-240. https://doi.org/10.1016/j.cageo.2010.09.004

Ullman S (1979) The interpretation of structure from motion. In: Proceedings of the Royal Society of London. Series B. Biological Sciences. pp 405-426

Varnes DJ (1978) Slope Movement Types and Processes. Special Report. 176:11-33

Vaziri A, Moore L, Ali H (2010) Monitoring systems for warning impending failures in slopes and open pit mines. Nat Hazards 55:501-512. https://doi.org/10.1007/s11069-010-9542-5

Voight B (1988) A method for prediction of volcanic eruptions. Nature 332:125-130. https://doi.org/10.1038/332125a0

Voight B (1989) A relation to describe rate-dependent material failure. Science (80- ) 243:200-203. https://doi.org/10.1126/science.243.4888.200

Voight B, Kennedy BA (1979) Slope failure of 1967-1969, Chuquicamata Mine, Chile. Dev Geotech Eng 14:595-632. https://doi.org/10.1016/B978-0-444-41508-0.50025-9

Westoby MJ, Brasington J, Glasser NF, Hambrey MJ, Reynolds JM (2012) "Structure-from-Motion" photogrammetry: A low-cost, effective tool for geoscience applications. Geomorphology 179:300314. https://doi.org/10.1016/j.geomorph.2012.08.021

Xiang J, Chen J, Sofia G, Tian Y, Tarolli P (2018) Open-pit mine geomorphic changes analysis using multi-temporal UAV survey. Environ Earth Sci 77:. https://doi.org/10.1007/s12665-018-7383-9

Zienkiewicz OC, Humpheson C, Lewis RW (1975) Associated and non-associated visco-plasticity and plasticity in soil mechanics. Geotechnique 25:671-689. https://doi.org/10.1680/geot.1975.25.4.671

\section{Acknowledgements}

The photos taken on 25 January 2019 at Las Cruces open-pit mine were provided by Ecologistas en Acción Sevilla. First author shows gratitude for the working contract arranged with HEMAV SL for the development of the project and second author for the PhD student contract BES-2014-069076. This work was supported by the Regional Administration of Madrid (Comunidad de Madrid) in the framework of the Industrial PhD Project GEODRON (IND2017/AMB-7789). Also, it has been partially funded by U- 
GEOHAZ project co-funded by the European Commission, Directorate-General for Humanitarian Aid and Civil Protection (ECHO), under the call UCPM-2017-PP-AG; and E-SHAPE project co-funded by the European Union's Horizon 2020 research and innovation programme under grant agreements 820852 .

Fig. 1 Study area and geological map of the upper part of the Guadalquivir basin (adapted from Instituto Geológico y Minero de España 2008)

Fig. 2 Pre-failure scenario. a Orthoimage (Instituto Geográfico Nacional 2019) and layout of Las Cruces open-pit mine (adapted from First Quantum Minerals Ltd. 2015). Black line: cross-section profile trace. White box: photogrammetry processing spatial extent. White dashed box: 3D geo-mechanical modeling spatial extent. b Cross-section of the north slope and lithostratigraphic sequence (adapted from Montero et al. 2009, Cooper et al. 2011 and First Quantum Minerals Ltd. 2015)

Fig. 3 Orthoimages of the failure area. a Prefailure orthoimage (Instituto Geográfico Nacional 2019) from February 2016. b Post-failure orthoimage from January 2019

Fig. 4 Post-failure scenario. a Detail of the slope failure and main geomorphic features. White line: crosssection profile trace. b Cross-section of the north slope and main lithostratigraphic units. Blue line fill pattern: initial moving mass volume estimate. Red line fill pattern: refined moving mass volume estimate

Fig. 5 LOS velocity maps for the year prior to the failure (from 4 January 2018 to 17 January 2019). a Ascending velocities. b Descending velocities

Fig. 6 Mean LOS displacement time series for the year prior to the failure (from January 2018 to January 2019). a Mapped areas. b Accumulated displacements over the north slope. c Mean velocities over the mapped areas. Accumulated displacements over the $\mathbf{d}$ processing plant, e south dump, f north dump 1 and g north dump 2

Fig. 7 LOS inverse velocity plots of the mapped areas. a Inverse velocity plots of the north slope. Red squares: period from 1 September to 31 December 2018. Inverse velocity plots of the north slope obtained from the $\mathbf{b}$ ascending and $\mathbf{c}$ descending datasets for the period from 1 September to 31 December 2018. Black dashed lines: linear regressions for the whole period. Red dashed line: linear regression for the period from 7 October to 31 December 2018. Inverse velocity plots of the $\mathbf{d}$ south dump, e north dump 1 and $\mathbf{f}$ north dump 2, respectively

Fig. 8 a 3D finite element mesh. b Pore pressure contours (in $\mathrm{Pa}$ ). White line: cross-section profile trace

Fig. 9 3D stability analysis: failure mechanism for the computed Safety Factor $S F=1.20$. a Displacement contours (in $\mathrm{m}$ ) at failure. b Cross-section of the displacement contours at failure (in $\mathrm{m}$ ). $\mathbf{c}$ Cross-section of the equivalent plastic strain contours at failure. White line: cross-sections profile trace

Fig. 10 Soil water retention curve of the Blue Marls (Boza 2014)

Fig. 11 2D finite element mesh for $\mathbf{a}$ the stability analysis in peak conditions and $\mathbf{b}$ the back-analysis in mobilized conditions. c Pore pressure contours (in $\mathrm{Pa}$ ) for the three pore pressure scenarios. Degree of saturation $\mathrm{Sr}$ for the $\mathbf{d} 300-\mathrm{kPa}$ - and e $150-\mathrm{kPa}$-suction cases

Fig. 12 Mesh size influence on the stability analysis

Fig. 13 2D stability analysis: failure mechanisms for the three pore pressure scenarios. a Displacement contours (in $\mathrm{m}$ ) at failure. b Equivalent plastic strain contours at failure

Table 1 Geo-mechanical properties (adapted from Gens and Alonso 2006, Montero et al. 2009, Cooper et al. 2011, Boza 2014 and First Quantum Minerals Ltd. 2015). N.A.: not applicable 


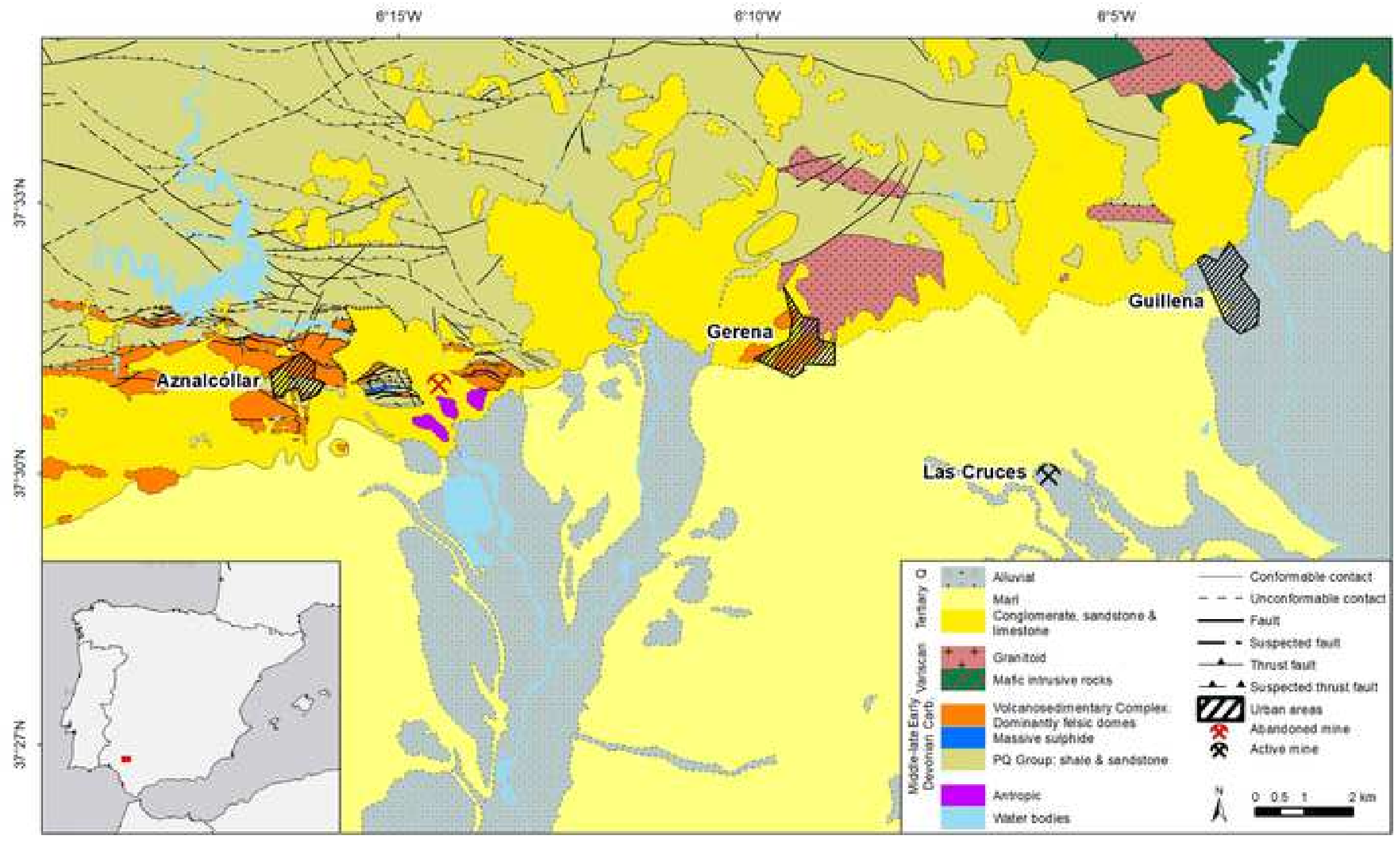




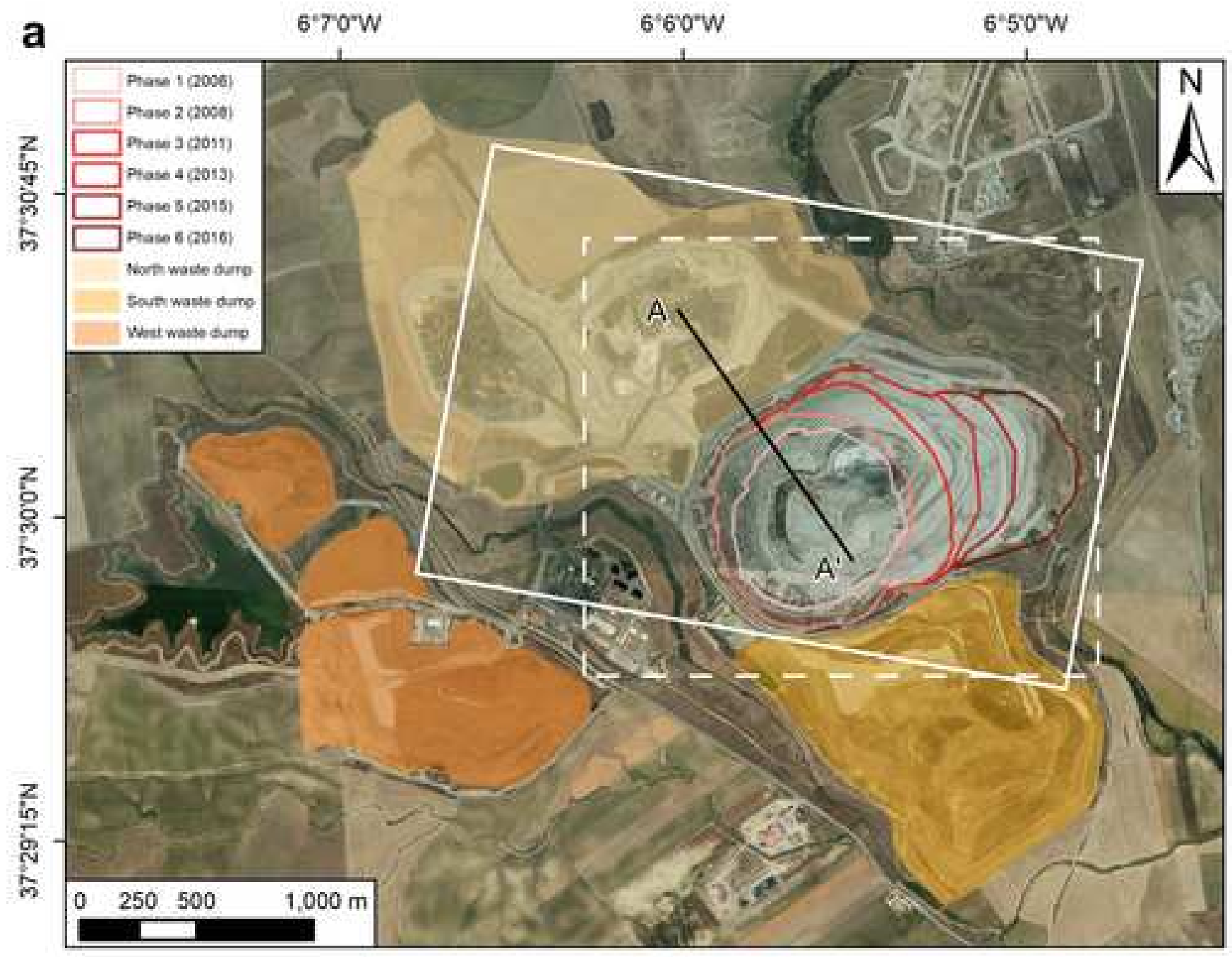

b

[ma.sil.]

100

so

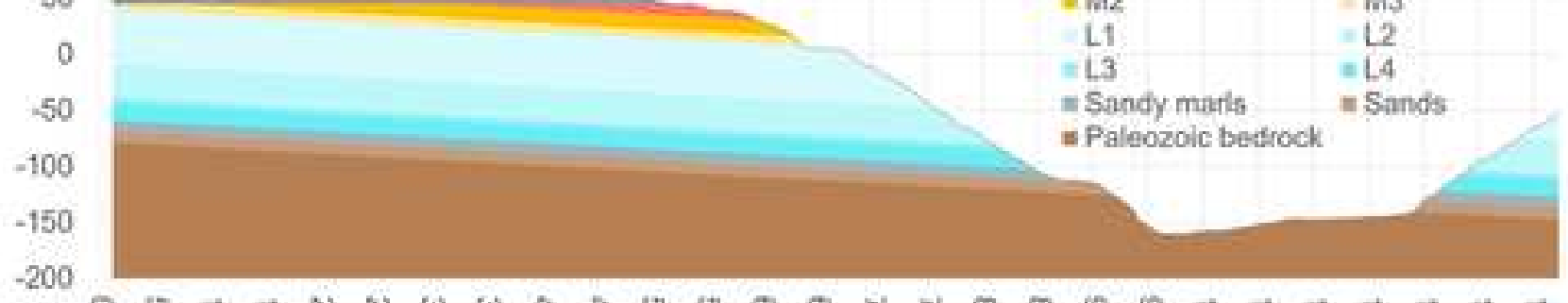

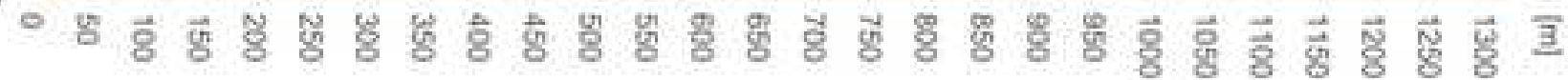



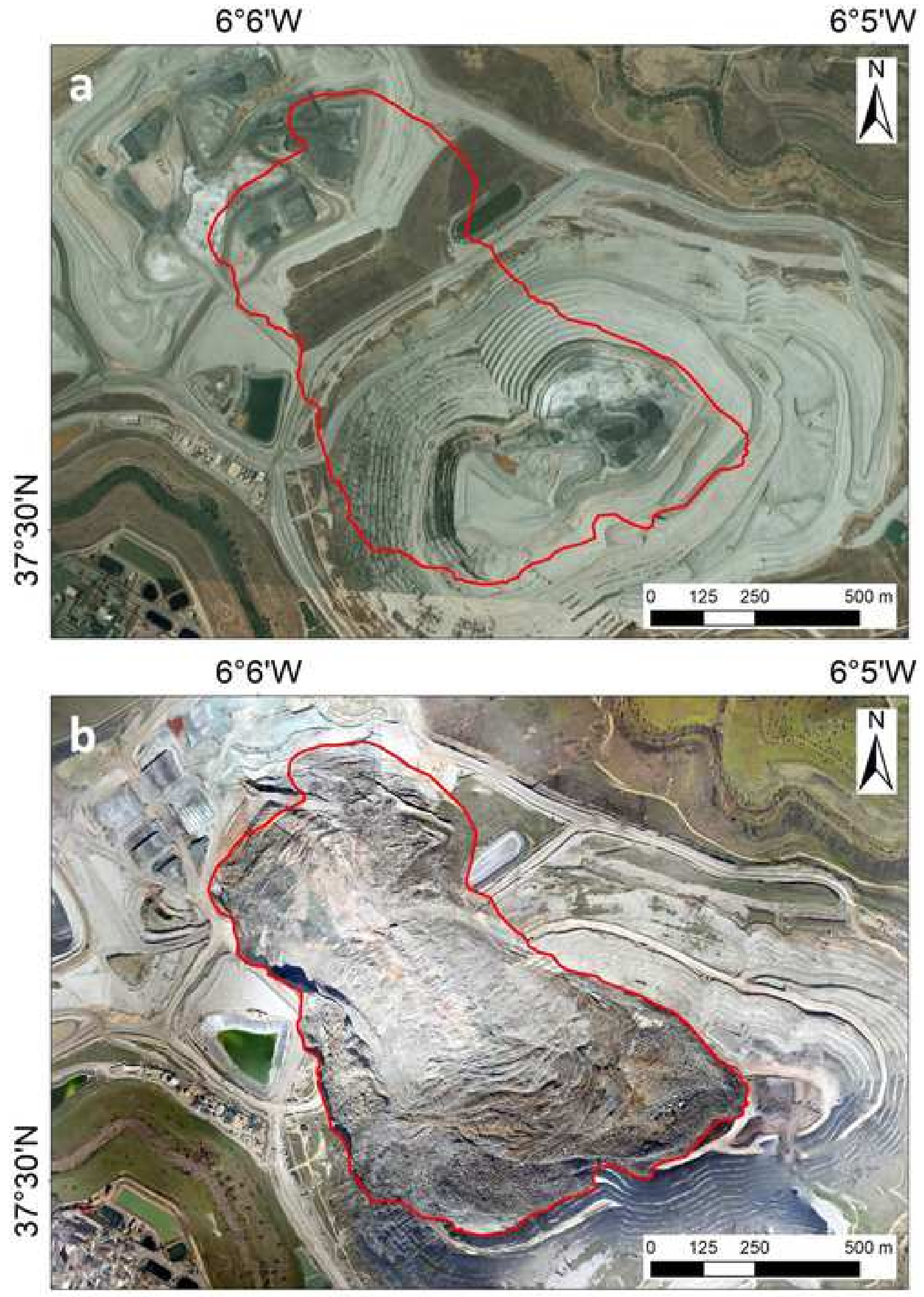
a

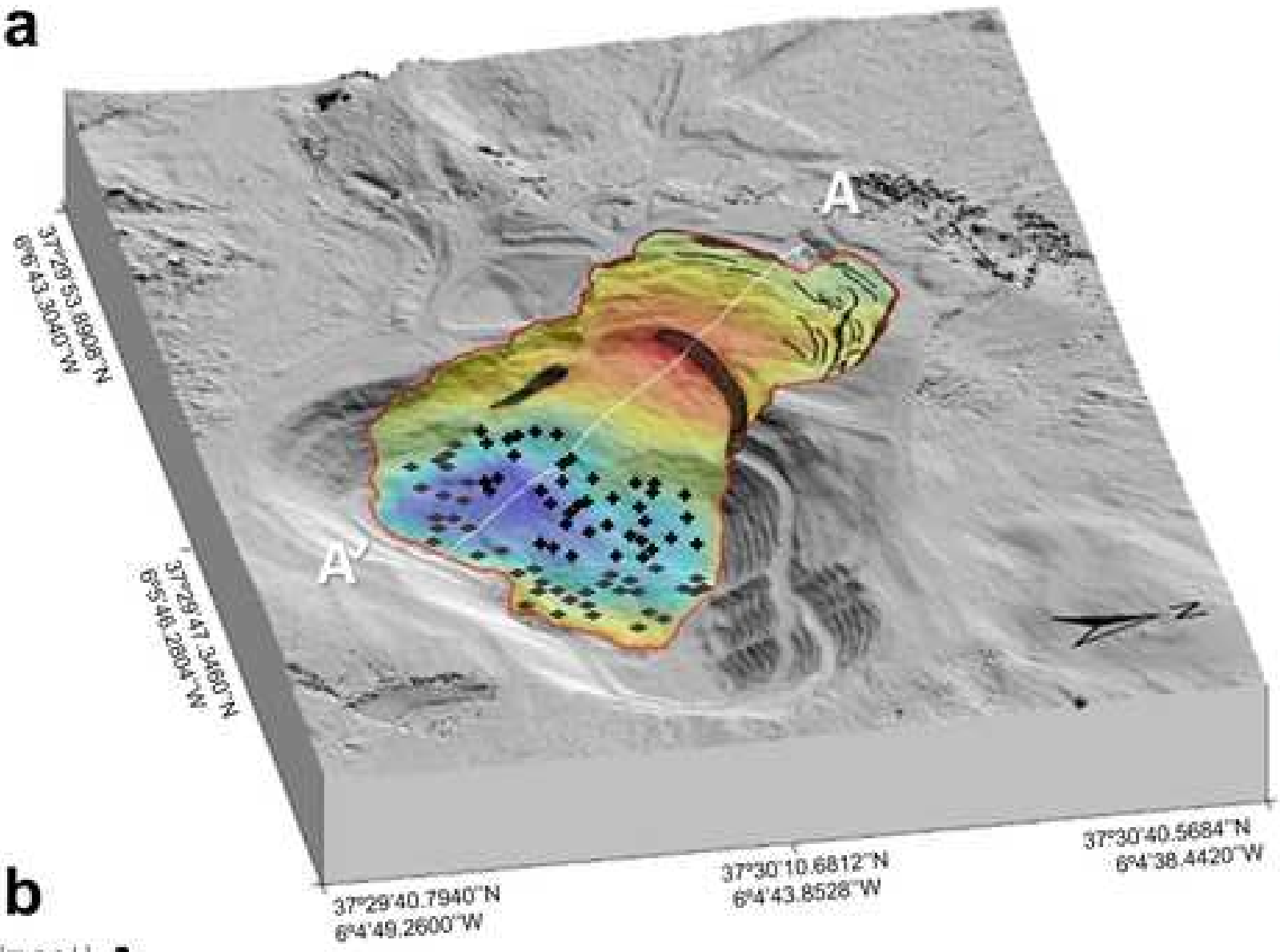

\section{Geomorphology}

- scarps

+ Mudflow

$\checkmark$ Debris

Exposed shear plane

$\square$ Landslide external boundary

Cross-section profile trace

Elevation change after the failure ( $\mathrm{m})$

High : 106.072

Low : -79.4903

[mast] $\mathbf{A}$

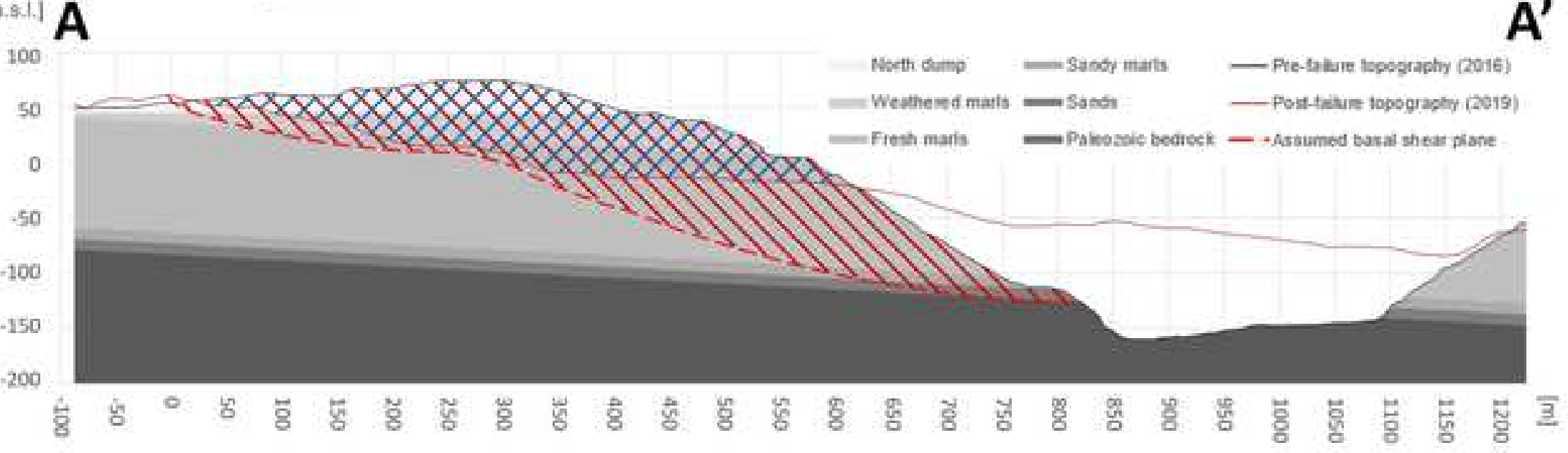



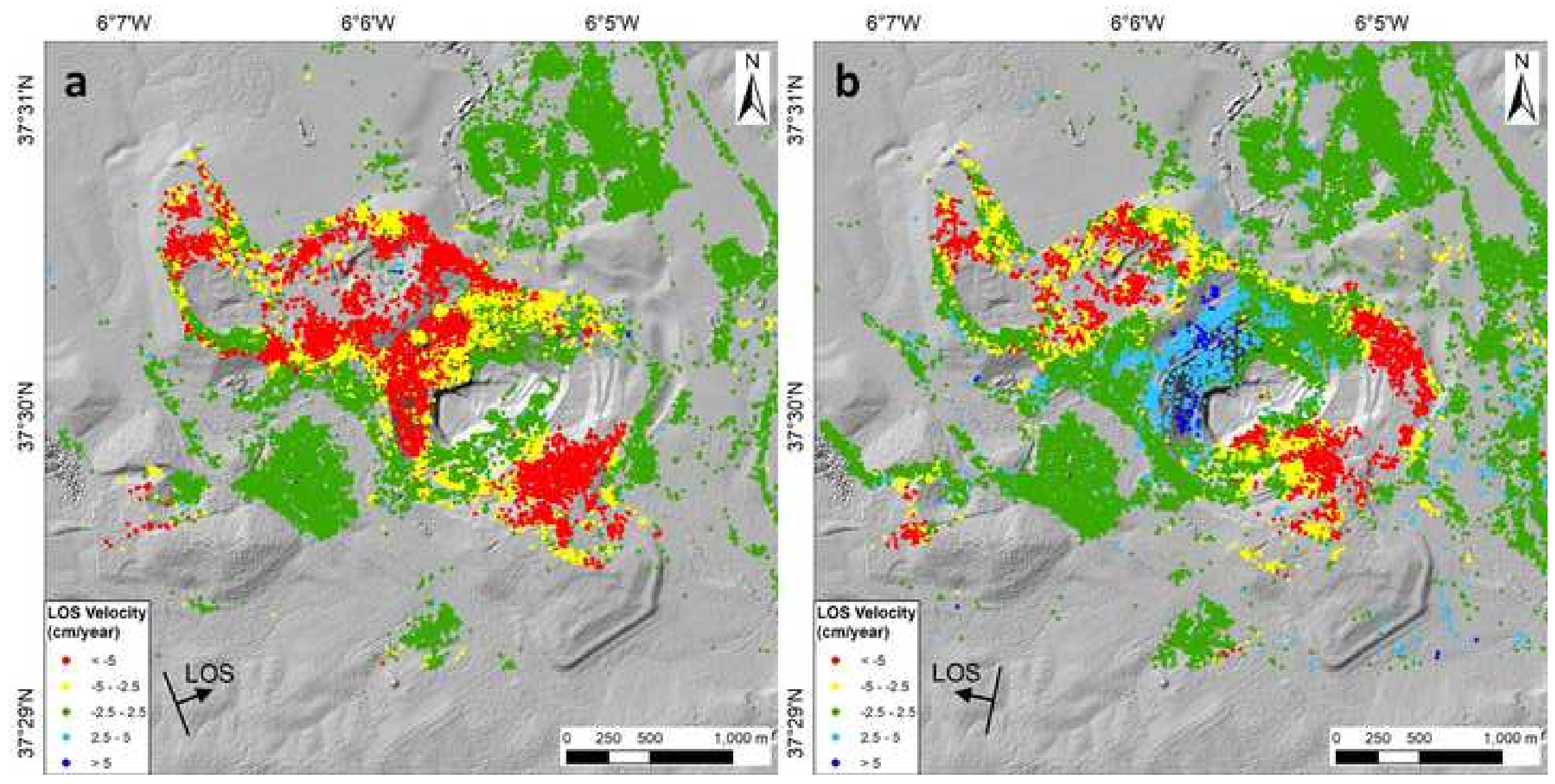


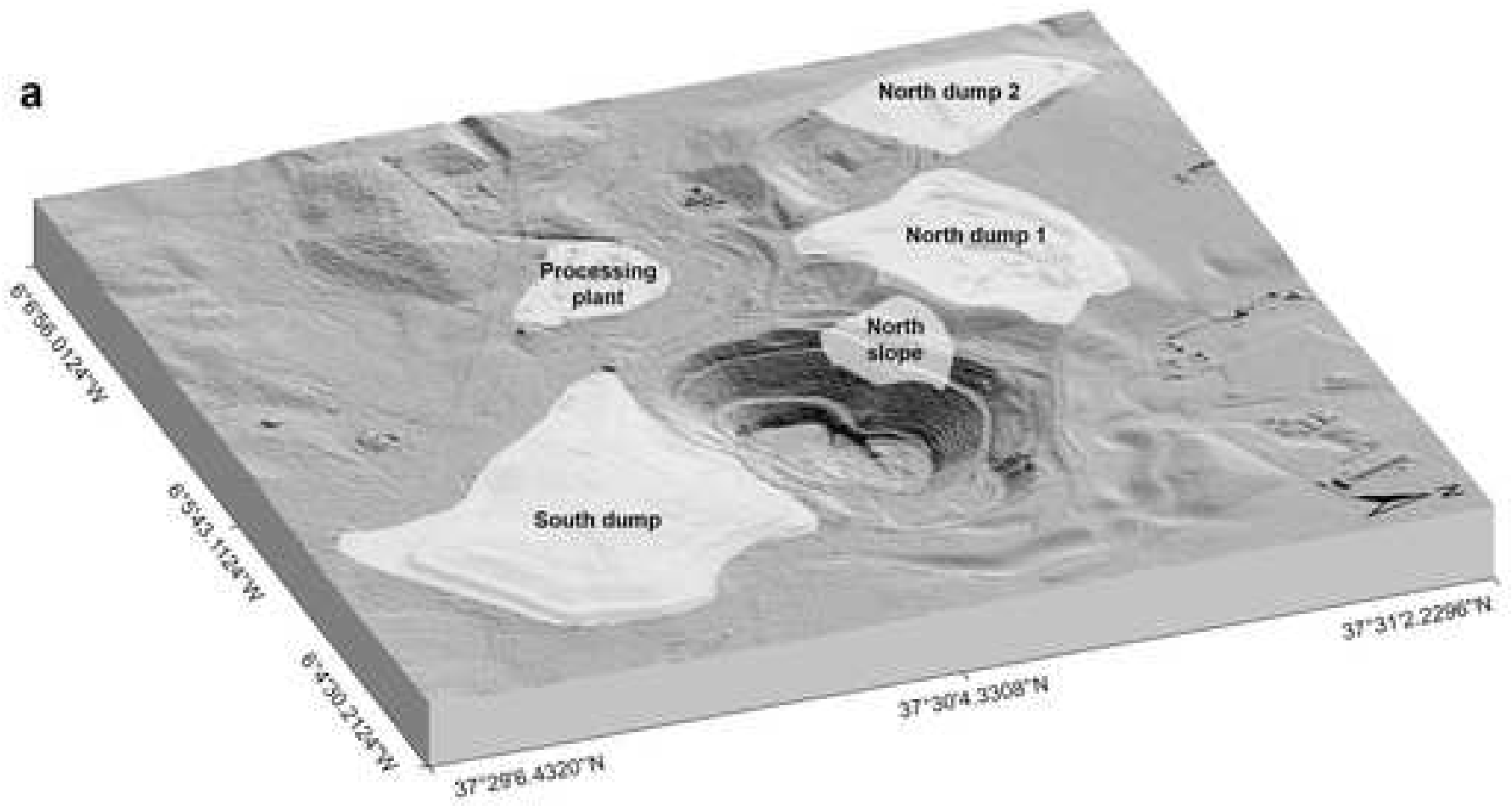

b
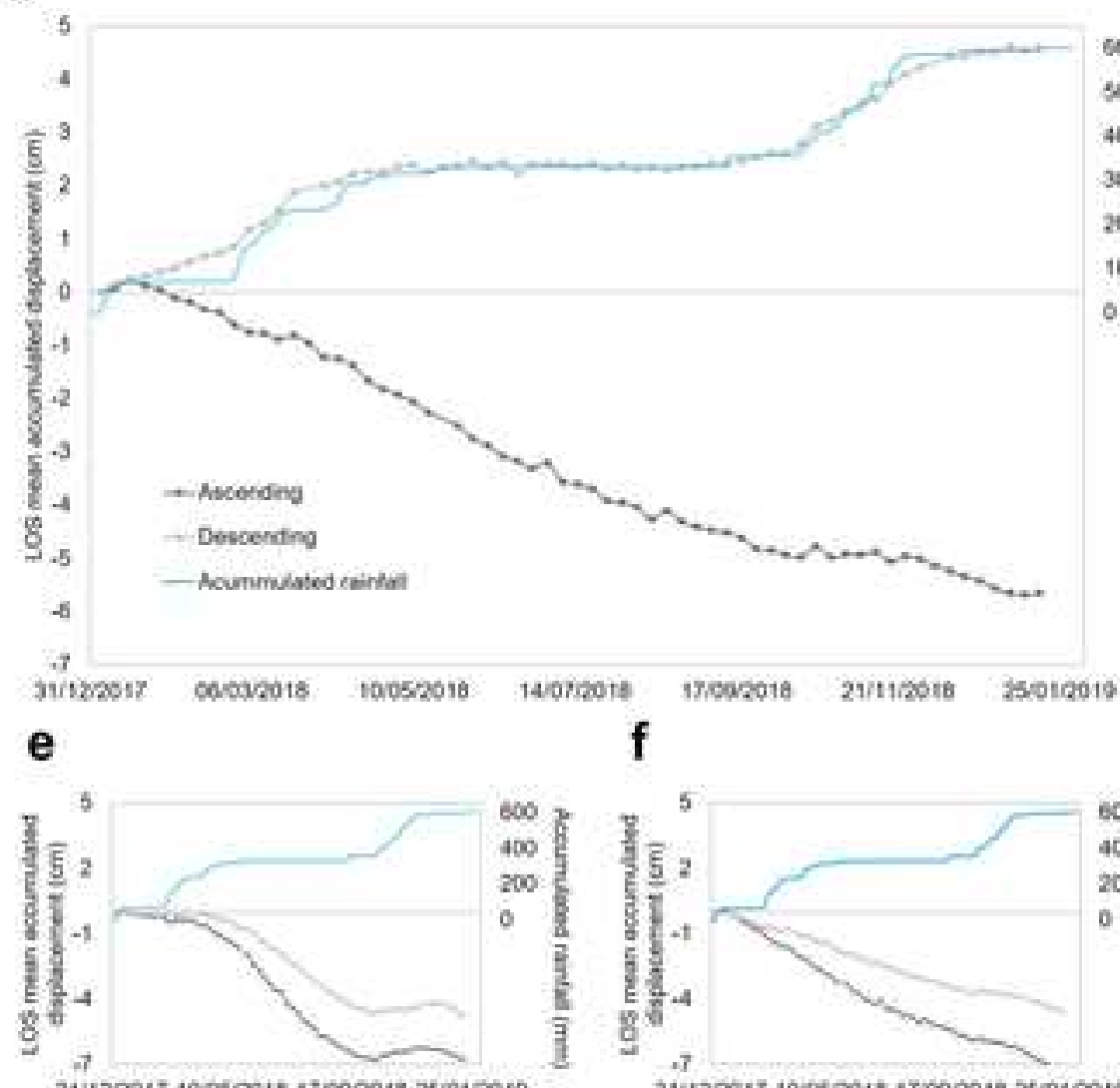

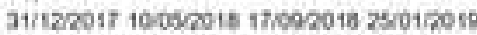

600
400
400
300
200
100
0.8

\begin{tabular}{|c|c|c|}
\hline C & Los mean & aty (cmlyoat) \\
\hline Atese & Ascenting & Desconding \\
\hline Procesing plavt & Q.t & 0 \\
\hline Nom wlope & 62 & 37 \\
\hline South dump & -63 & -59 \\
\hline Ninth dome 1 & i.t & 45 \\
\hline Nowh durme? & .56 & A1 \\
\hline
\end{tabular}

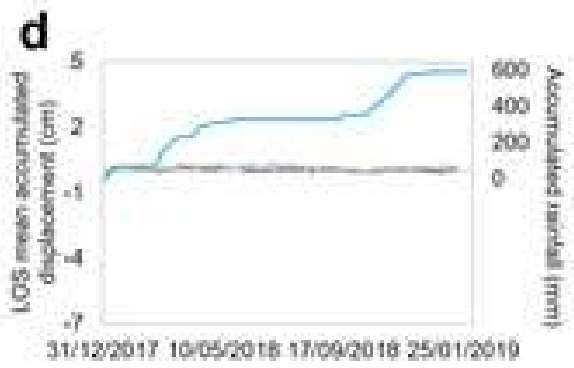

g

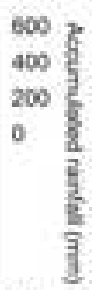

311322057 10082018 1700201325012019

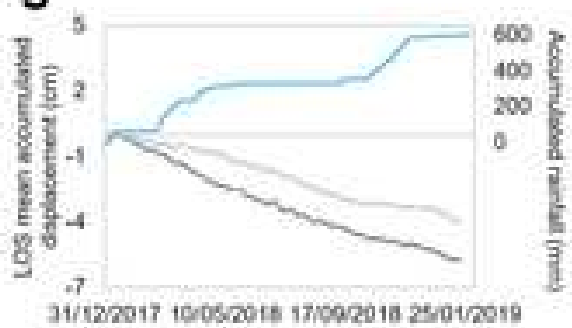


a

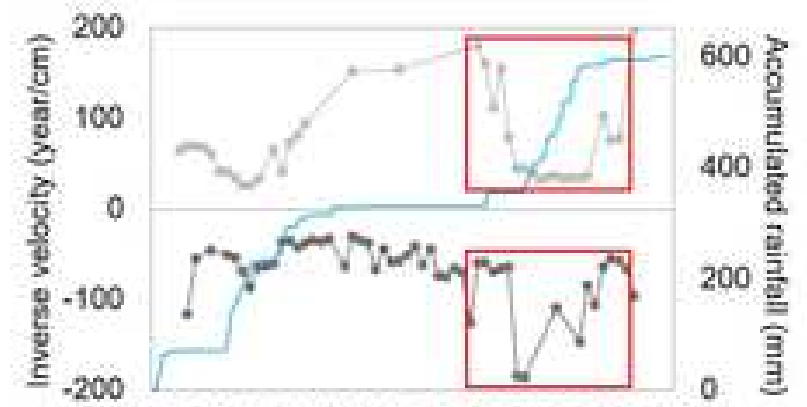

$31 / 12 / 2017$ 10/05/2018 17/09/2018 25/01/2019

\section{d}

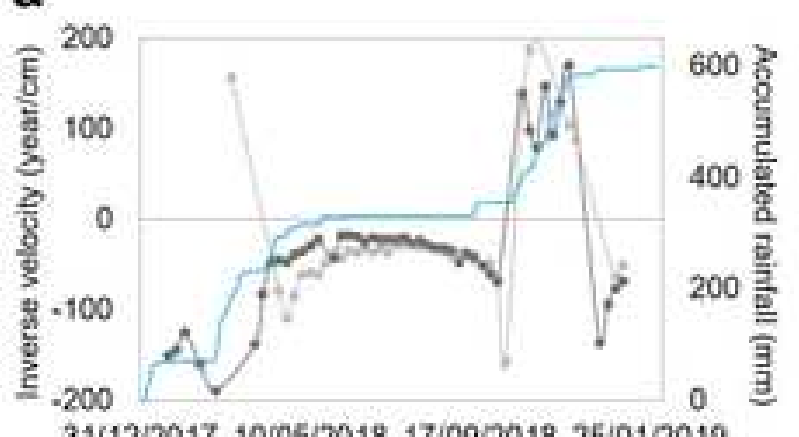

b

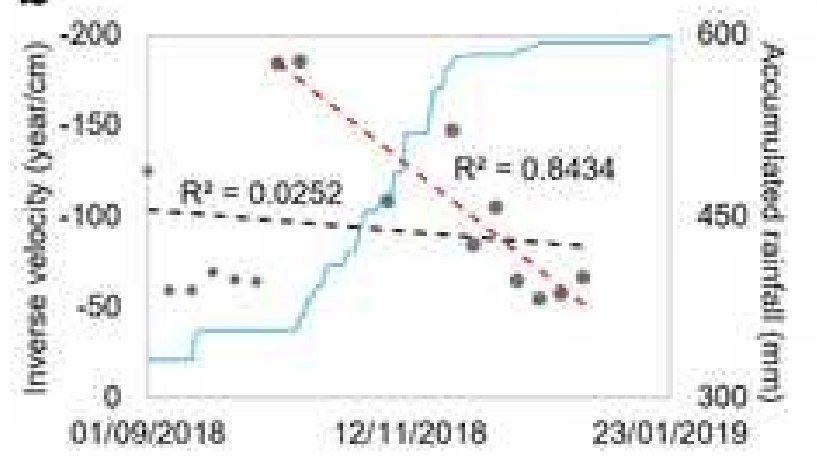

e

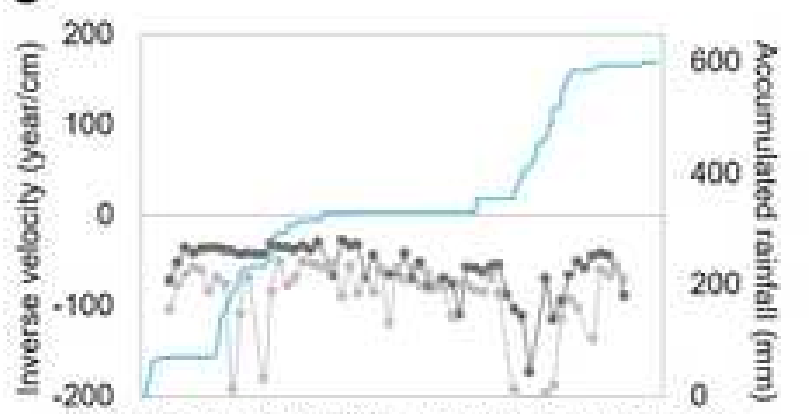

$31 / 12 / 2017$ 10/05/2018 17/09/2018 25/01/2019 c

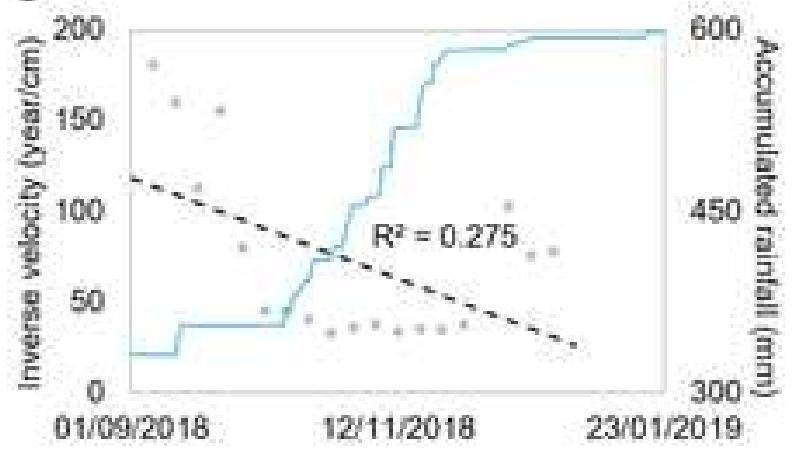

f

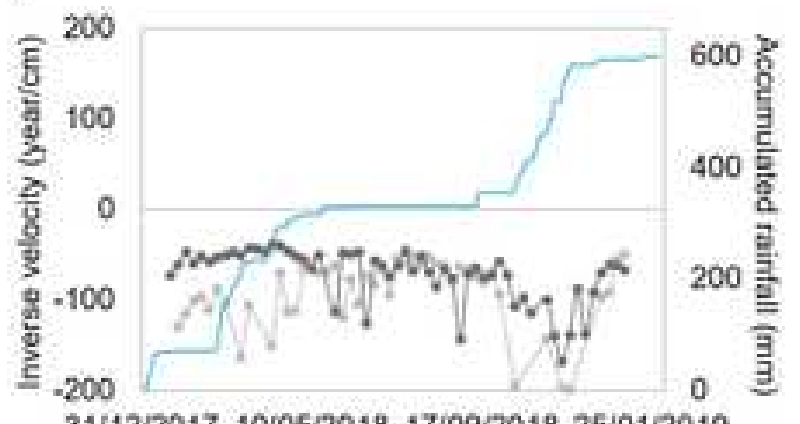

$\rightarrow$ Ascending $\rightarrow$ Descending -Acummulated rainfall 


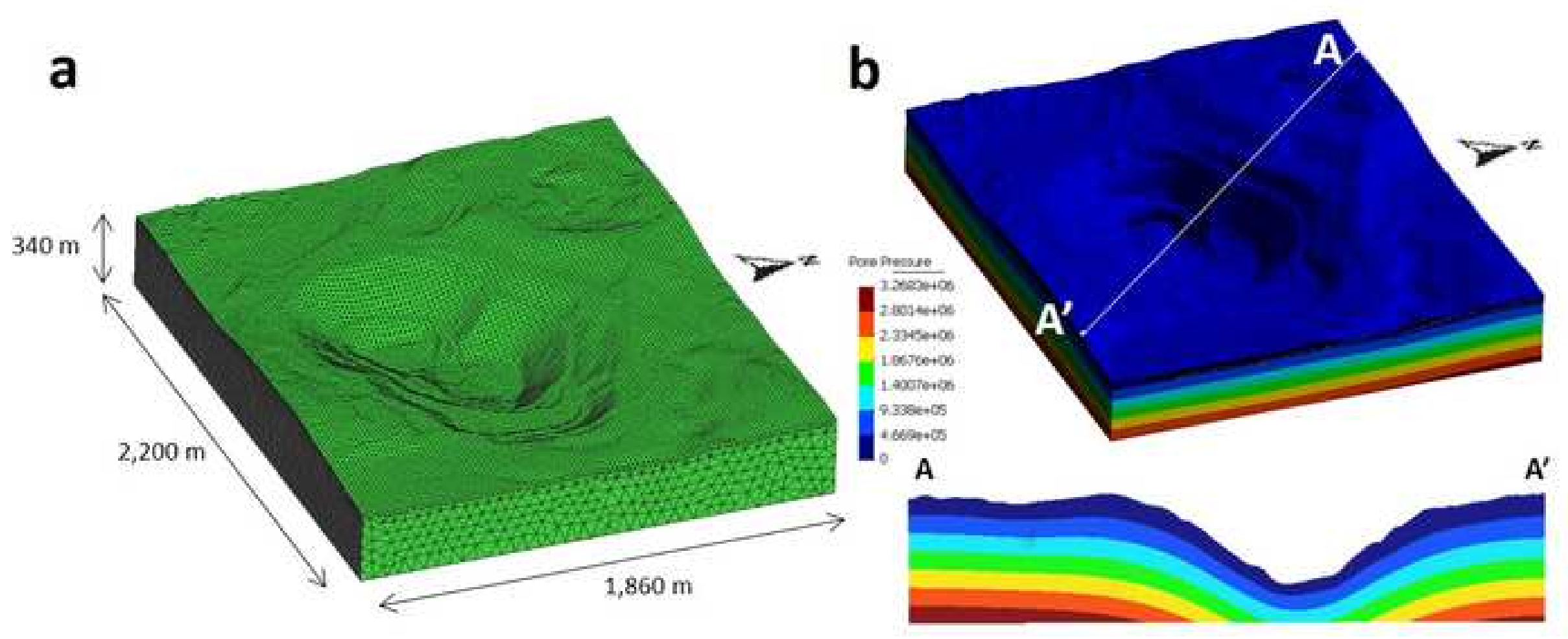



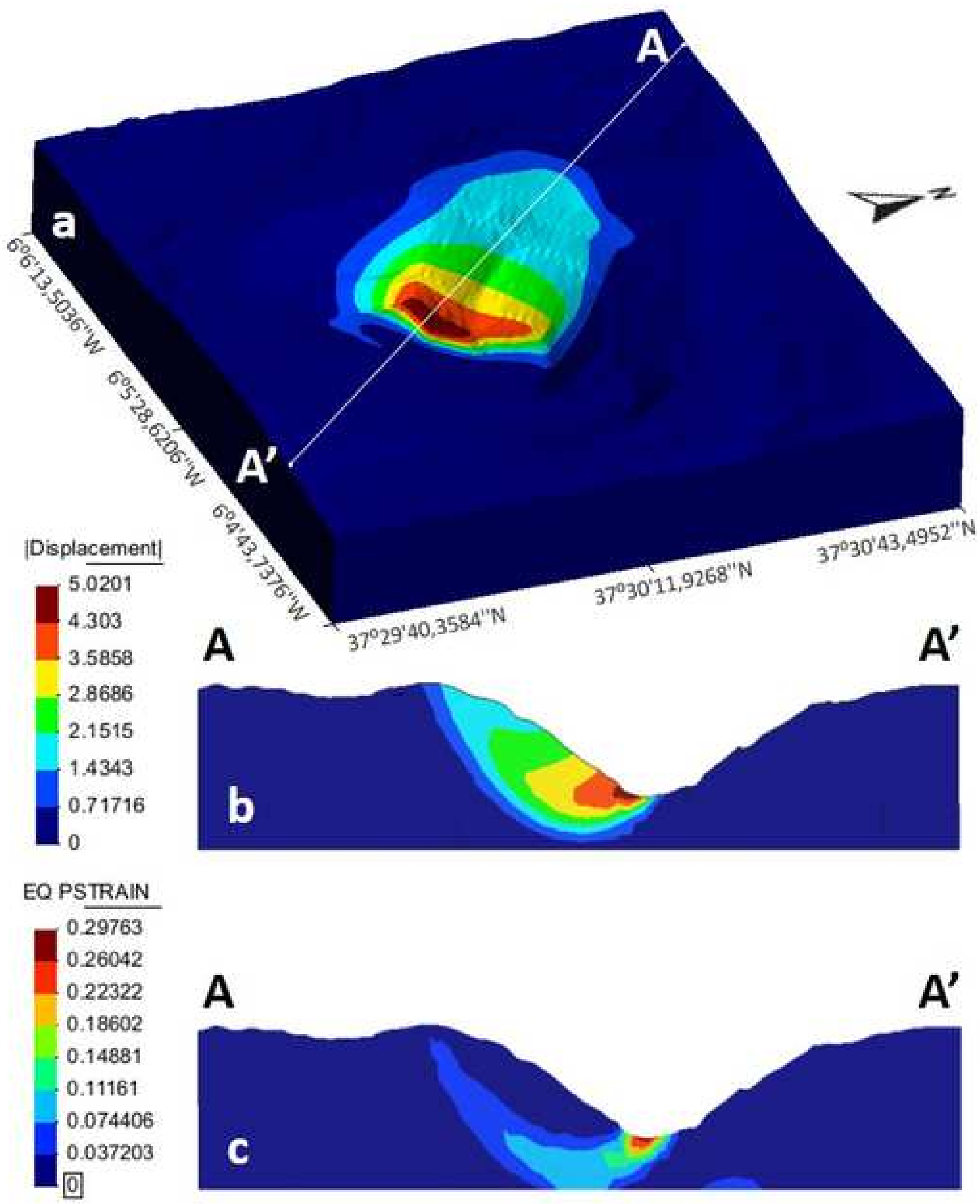


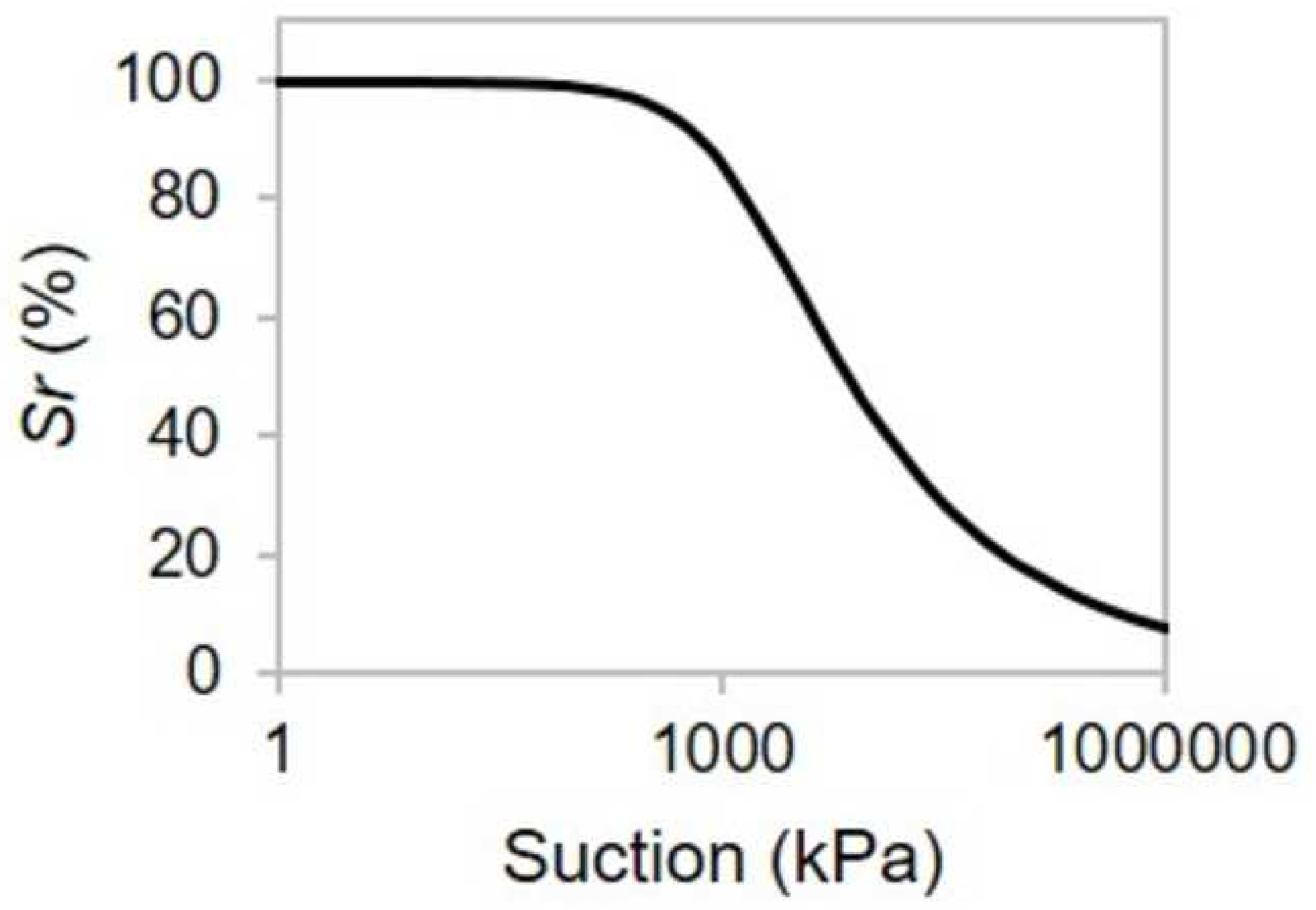


a

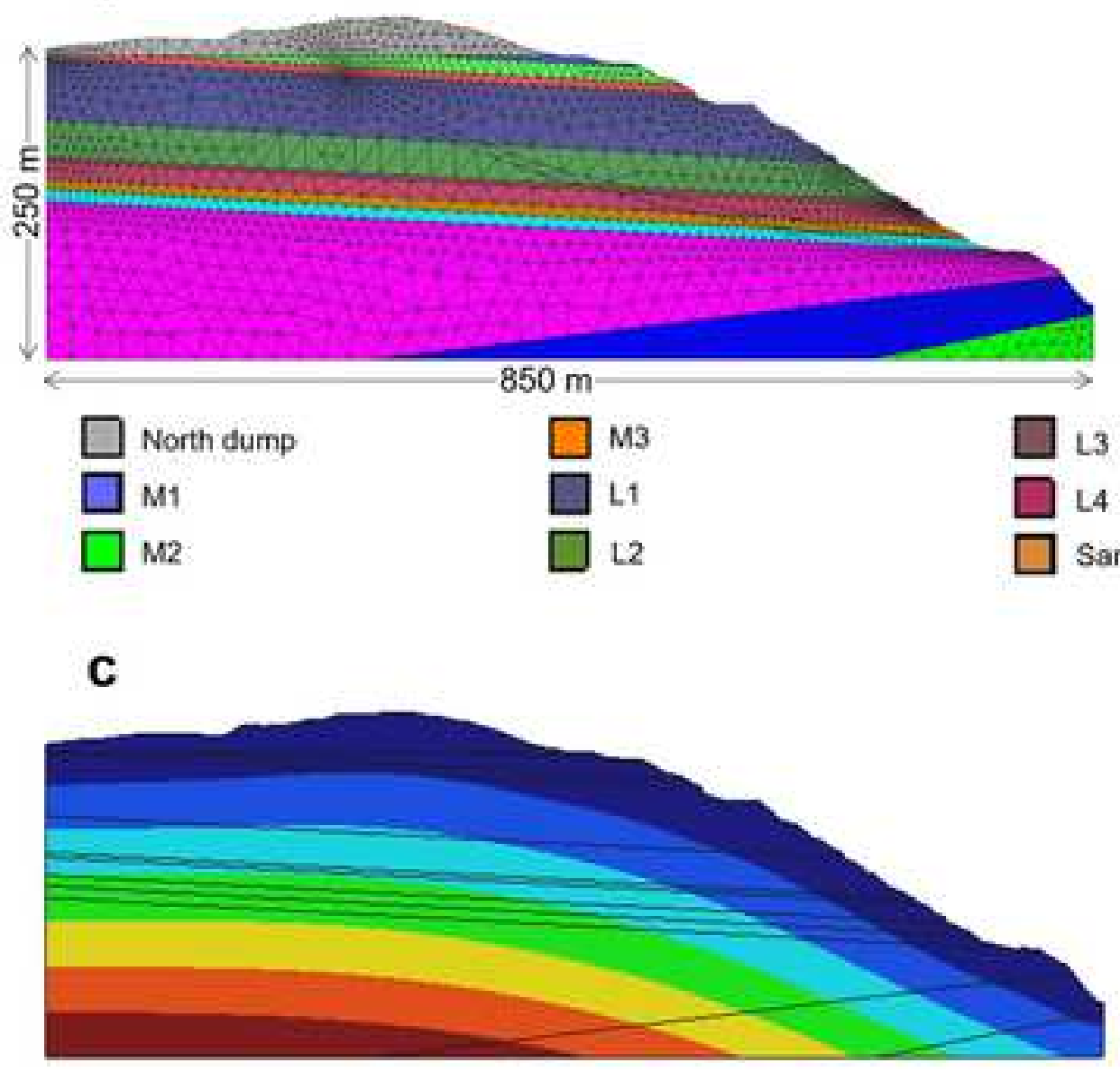

d

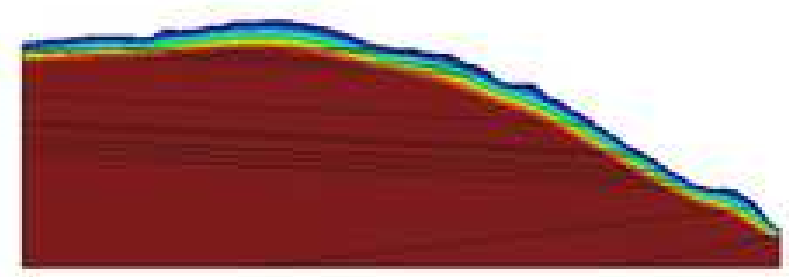

b

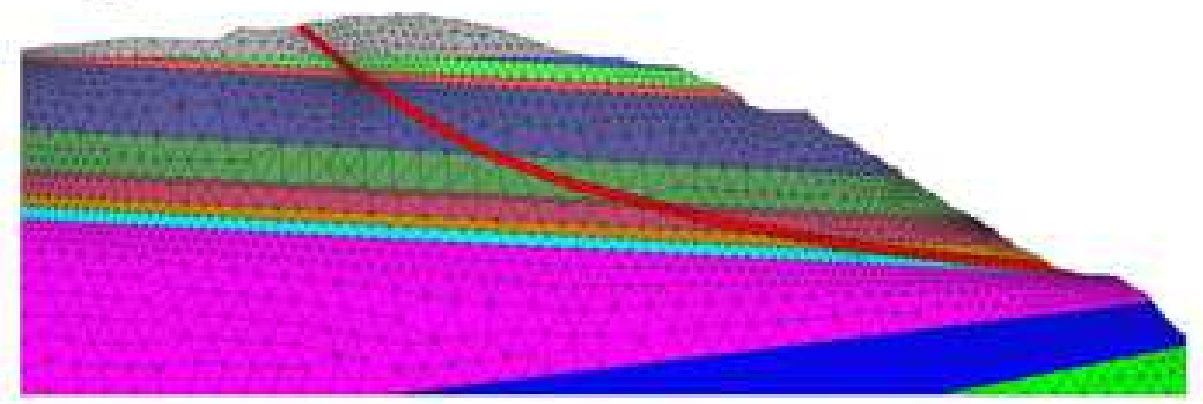

$\square$ Sands
$\square$ Shales
Tuffs

\begin{tabular}{|l|} 
(300 kPa suction) \\
\hline Saturation \\
0.97506 \\
0.99013 \\
0.98519 \\
0.96055 \\
0.97532 \\
0.97038 \\
0.96544 \\
\hline
\end{tabular}

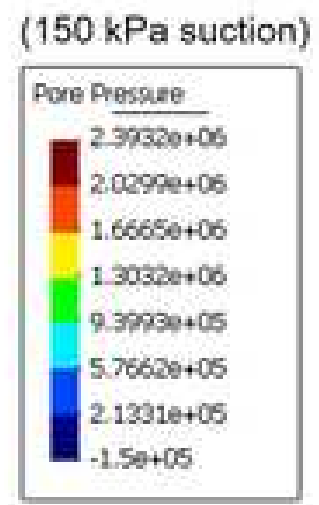

e

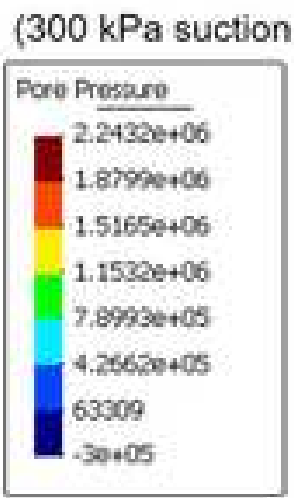

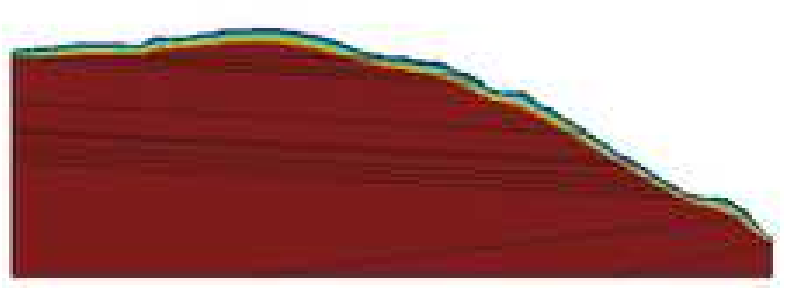

$\square$ sulfides

Falure surface

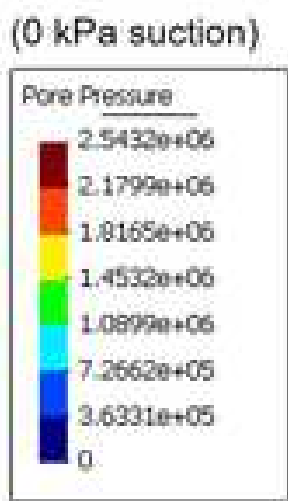

(150 kPa suction)

\begin{tabular}{|l|}
\hline Saturaton \\
$\mathbf{D}_{0.99796}^{1}$ \\
0.99593 \\
0.97999 \\
0.99106 \\
0.90962 \\
0.98778 \\
0.96575 \\
\hline
\end{tabular}




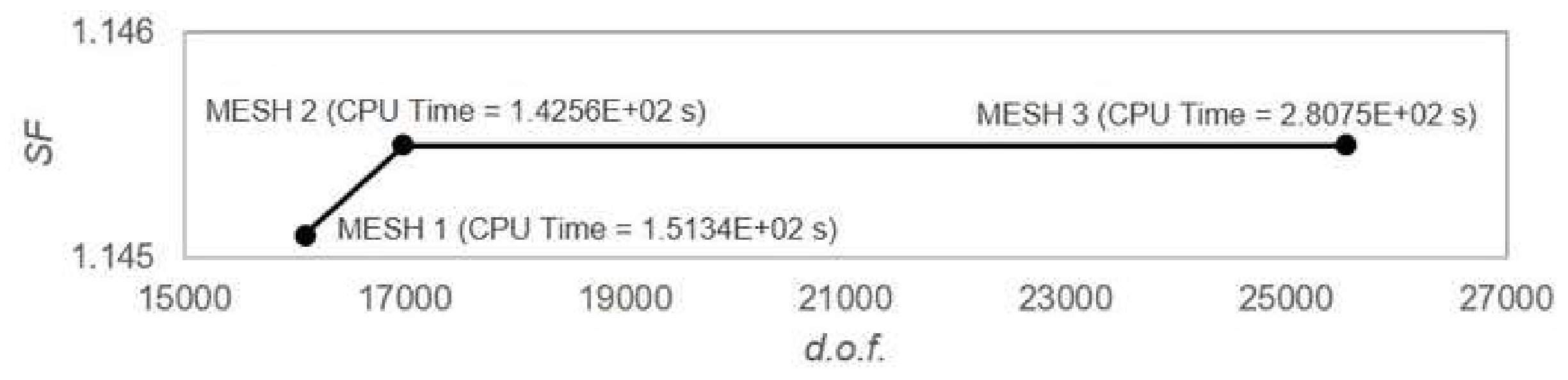


a

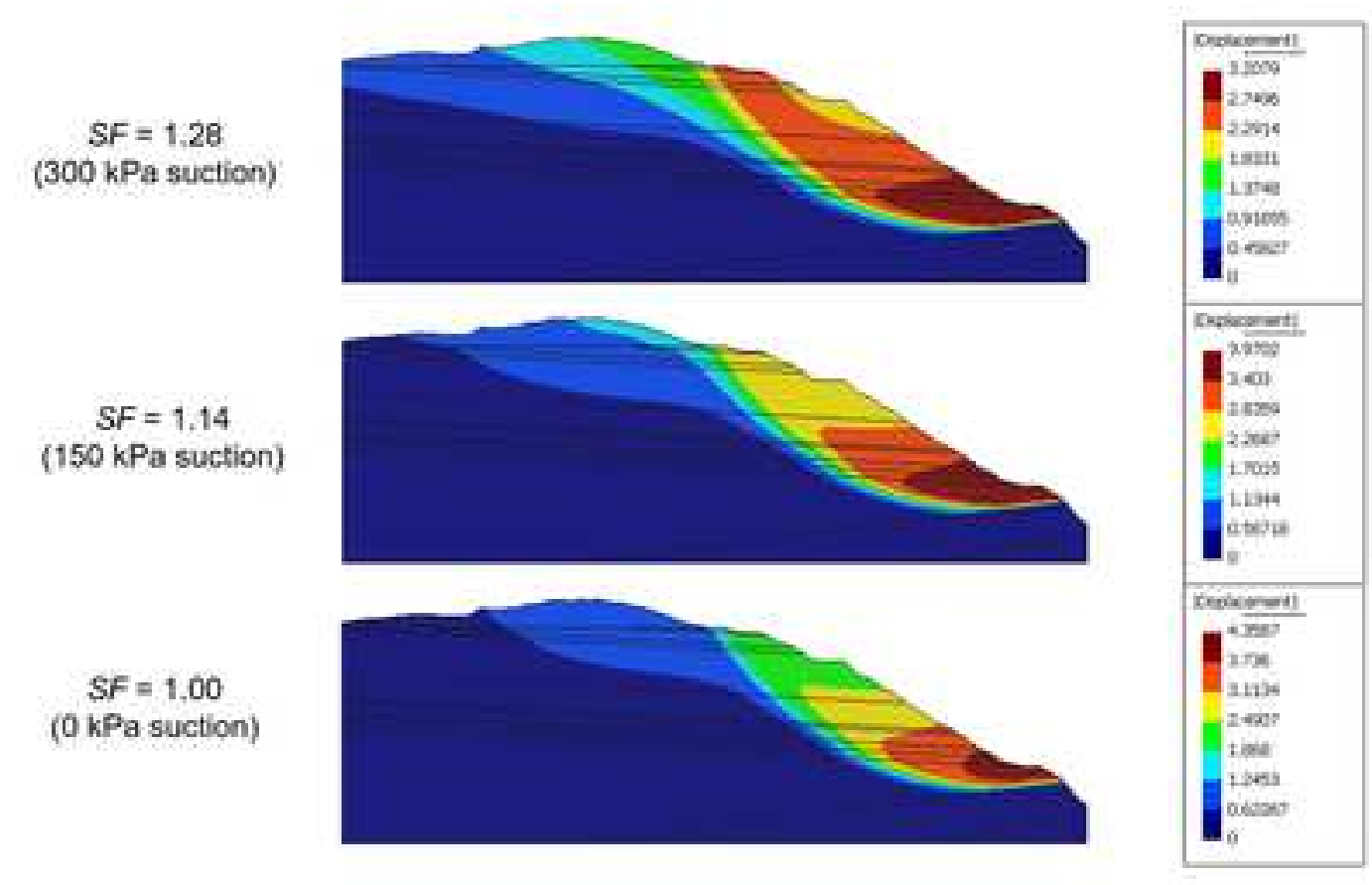

b

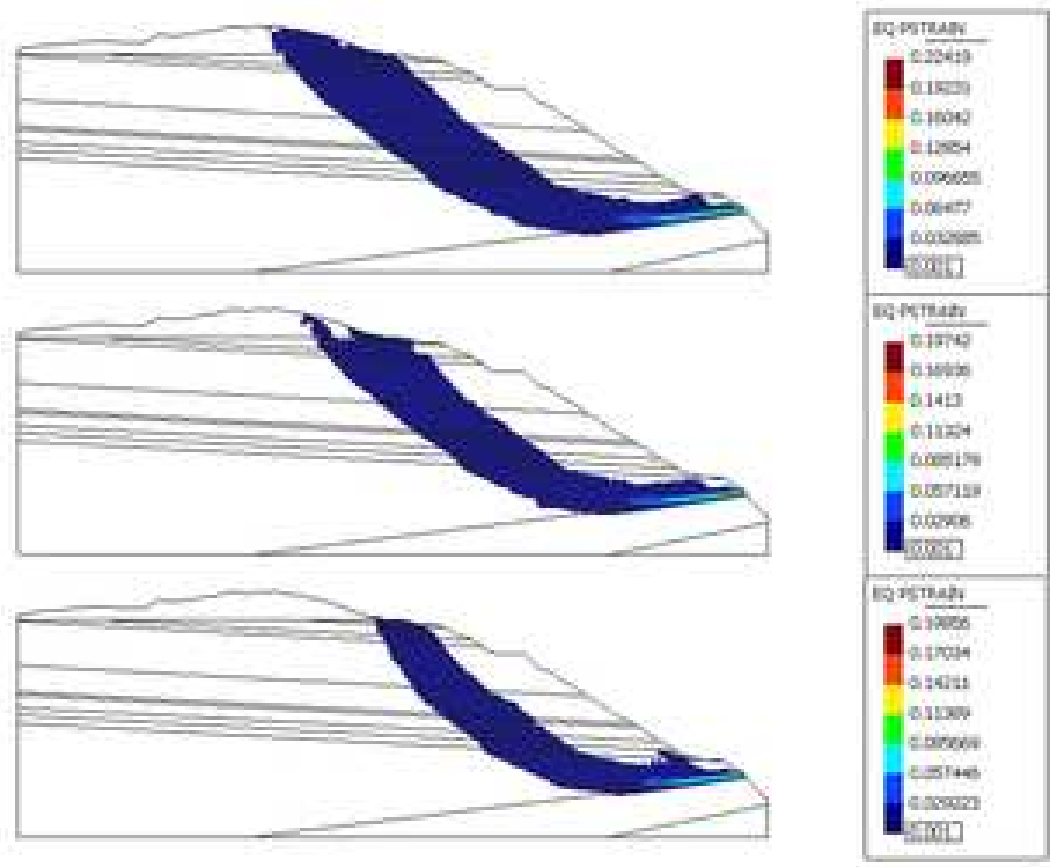




\begin{tabular}{|l|l|l|l|l|l|l|l|}
\hline Material & $\begin{array}{l}\text { Footwall } \\
\text { elevation } \\
{[\mathrm{m} \text { a.s.1.] }}\end{array}$ & $\begin{array}{l}\text { Wet bulk } \\
\text { density } \\
{\left[\mathrm{kgm}^{-3}\right]}\end{array}$ & $\begin{array}{l}\text { Void } \\
\text { ratio }\end{array}$ & $\begin{array}{l}\text { Young } \\
\text { modulus } \\
{\left[\mathrm{kNm}^{-2}\right]}\end{array}$ & $\begin{array}{l}\text { Poisson } \\
\text { ratio }\end{array}$ & $\begin{array}{l}\text { Friction } \\
\left.\text { angle [ }{ }^{\circ}\right]\end{array}$ & $\begin{array}{l}\text { Cohesion } \\
{\left[\mathrm{kNm}^{-2}\right]}\end{array}$ \\
\hline North dump & +35 & $1,946.96$ & 0.81 & $4.5 \cdot 10^{4}$ & 0.3 & 25 & 62 \\
\hline M1 & +25 & $1,892.71$ & 0.92 & $2.8 \cdot 10^{4}$ & 0.33 & 22 & 110 \\
\hline M2 & +12 & $1,921.51$ & 0.86 & $6 \cdot 10^{4}$ & 0.33 & 21 & 150 \\
\hline M3 & +4 & $1,946.96$ & 0.81 & $7 \cdot 10^{4}$ & 0.33 & 21 & 150 \\
\hline L1 & -45 & $1,968.36$ & 0.77 & $1.06 \cdot 10^{5}$ & 0.33 & 20 & 210 \\
\hline L2 & -75 & $2,002.34$ & 0.71 & $1.5 \cdot 10^{5}$ & 0.33 & 18 & 270 \\
\hline L3 & -80 & $1,996.51$ & 0.72 & $1.5 \cdot 10^{5}$ & 0.33 & 18 & 270 \\
\hline L4 & -95 & $2,020.24$ & 0.68 & $2.25 \cdot 10^{5}$ & 0.33 & 18 & 280 \\
\hline Sandy marls & -105 & $2,026.35$ & 0.67 & $3 \cdot 10^{5}$ & 0.33 & 31 & 85 \\
\hline Sands & -115 & $2,045.12$ & 0.64 & $3 \cdot 10^{5}$ & 0.3 & 37 & 20 \\
\hline Shales & N.A. & 2,400 & 0 & $5 \cdot 10^{6}$ & 0.25 & 21.5 & 90 \\
\hline Tuffs & N.A. & 2,100 & 0 & $5 \cdot 10^{6}$ & 0.25 & 35 & 500 \\
\hline Sulphides & -250 & 2,100 & 0 & $5 \cdot 10^{6}$ & 0.25 & 35 & 500 \\
\hline Failure surface & N.A. & $1,979.43$ & 0.75 & $1.4 \cdot 10^{5}$ & 0.3 & 12 & 10 \\
\hline
\end{tabular}

